\title{
Post-transcriptional regulation of mouse neurogenesis by Pumilio proteins
}

\author{
Meng Zhang, ${ }^{1,2}$ Dong Chen, ${ }^{1,3}$ Jing Xia, ${ }^{1,2}$ Wenqi Han, ${ }^{4}$ Xiekui Cui, ${ }^{1,2}$ Nils Neuenkirchen, ${ }^{1,2}$ \\ Gretchen Hermes, ${ }^{5}$ Nenad Sestan, ${ }^{4,5,6,7,8}$ and Haifan Lin ${ }^{1,2,6,9}$ \\ ${ }^{1}$ Yale Stem Cell Center, Yale School of Medicine, New Haven, Connecticut 06520, USA; ${ }^{2}$ Department of Cell Biology, Yale School \\ of Medicine, New Haven, Connecticut 06520, USA; ${ }^{3}$ Department of Microbial Pathogenesis, Yale School of Medicine, New Haven, \\ Connecticut 06536, USA; ${ }^{4}$ Department of Neuroscience, Yale School of Medicine, New Haven, Connecticut 06510, USA; \\ ${ }^{5}$ Department of Psychiatry, Yale School of Medicine, New Haven, Connecticut 06511, USA; ${ }^{6}$ Department of Genetics, Yale School \\ of Medicine, New Haven, Connecticut 06520, USA; ${ }^{7}$ Section of Comparative Medicine, Program in Cellular Neuroscience, \\ Neurodegeneration, and Repair, Yale School of Medicine, New Haven, Connecticut 06520, USA; ${ }^{8}$ Yale Child Study Center, Yale \\ School of Medicine, New Haven, Connecticut 06519, USA; ${ }^{9}$ Department of Obstetrics and Gynecology, Yale School of Medicine, \\ New Haven, Connecticut 06520, USA
}

\begin{abstract}
Despite extensive studies on mammalian neurogenesis, its post-transcriptional regulation remains under-explored. Here we report that neural-specific inactivation of two murine post-transcriptional regulators, Pumilio 1 (Pum1) and Pum2, severely reduced the number of neural stem cells (NSCs) in the postnatal dentate gyrus (DG), drastically increased perinatal apoptosis, altered DG cell composition, and impaired learning and memory. Consistently, the mutant DG neurospheres generated fewer NSCs with defects in proliferation, survival, and differentiation, supporting a major role of Pum1 and Pum2 in hippocampal neurogenesis and function. Cross-linking immunoprecipitation revealed that Pum1 and Pum2 bind to thousands of mRNAs, with at least 694 common targets in multiple neurogenic pathways. Depleting Pum1 and/or Pum2 did not change the abundance of most target mRNAs but upregulated their proteins, indicating that Pum1 and Pum2 regulate the translation of their target mRNAs. Moreover, Pum1 and Pum2 display RNA-dependent interaction with fragile $X$ mental retardation protein (FMRP) and bind to one another's mRNA. This indicates that Pum proteins might form collaborative networks with FMRP and possibly other post-transcriptional regulators to regulate neurogenesis.
\end{abstract}

[Keywords: Pumilio; post-transcriptional regulation; hippocampus; neural stem cell; mRNA; FMRP; mouse]

Supplemental material is available for this article.

Received March 11, 2017; revised version accepted July 14, 2017.

Neurogenesis in mammals occurs mainly during prenatal and early postnatal development; afterward, it persists predominantly in two regions of the adult brain: the subgranular zone (SGZ) of the hippocampal dentate gyrus (DG) and the subventricular zone (SVZ) lining the lateral ventricles (Ming and Song 2011; Kempermann et al. 2015; Lim and Alvarez-Buylla 2016; Silbereis et al. 2016). In the hippocampus, neurogenesis begins with neural stem cell (NSC) divisions, which give rise to intermediate progenitor cells that will differentiate into migratory neuroblasts, immature neurons, and, eventually, mature neurons (Kempermann et al. 2015).

Extensive studies have revealed the delicate regulatory network of neurogenesis, involving the interplay of intracellular factors such as transcriptional factors (Ahmed et al. 2009; Lui et al. 2011; Nord et al. 2015; Shibata et al. 2015) and epigenetic regulators (Juliandi et al. 2010) as well as extracellular signals such as growth factors, neuro-

Corresponding author: haifan.lin@yale.edu

Article published online ahead of print. Article and publication date are online at http://www.genesdev.org/cgi/doi/10.1101/gad.298752.117. transmitters, hormones, and other morphogens (Lehtinen and Walsh 2011; Ramasamy et al. 2013; Zheng et al. 2016). In recent years, post-transcriptional regulation, which delivers much more rapid and subcellularly localized control of gene expression, especially has emerged as a critical aspect of neurogenesis and been implicated in virtually all steps of neurogenesis (DeBoer et al. 2013; Pilaz and Silver 2015). Despite this, relatively little is known about specific mechanisms that exert post-transcriptional regulation. A small number of studies have reported the role of microRNAs (miRNAs) (Han et al. 2016) in mediating post-transcriptional regulation, and less is known about miRNA-independent post-transcriptional regulation, which includes pre-mRNA processing, nuclear-tocytoplasmic transportation, stability control, and translational regulation (Änkö and Neugebauer 2012).

(c) 2017 Zhang et al. This article is distributed exclusively by Cold Spring Harbor Laboratory Press for the first six months after the full-issue publication date (see http://genesdev.cshlp.org/site/misc/terms.xhtml). After six months, it is available under a Creative Commons License (Attribution-NonCommercial 4.0 International), as described at http://creativecommons.org/licenses/by-nc/4.0/. 
Pumilio was originally discovered in Drosophila for its role in embryonic patterning (Lehmann and Nusslein-Volhard 1987). It belongs to the conserved PUF family (pumilio and fem-3 mRNA-binding factor) of RNA-binding proteins with members found throughout eukaryotes (Spassov and Jurecic 2003b). The defining feature of the PUF family is the conserved C-terminal RNA-binding domain (Pumilio homology domain [Pum-HD]) that consists of eight repeats of $\sim 36$ amino acids flanked by short conserved sequences on each side (Zamore et al. 1997).

Extensive studies in invertebrates have revealed the roles of PUF proteins in germline stem cell maintenance (Lin and Spradling 1997; Parisi and Lin 1999; Crittenden et al. 2002; Carreira-Rosario et al. 2016) and neuronal function (for review, see Baines 2005). It has also been reported in invertebrates that PUF proteins bind their target mRNAs by recognizing the conserved 32-nucleotide (nt) PRE (Pumilio response element) motif in the $3^{\prime}$ untranslated region (UTR) using their Pum-HD (Zhang et al. 1997). Upon binding, PUF proteins may exert effects on the stability, localization, and translation of their target mRNAs (for review, see Quenault et al. 2011). However, the biological functions and molecular mechanisms of the mammalian PUF proteins still remain largely underexplored.

In mammals, there are two PUF proteins: Pumilio 1 (Pum1) and Pum2. They are highly homologous. Recent works have shown that Pum 1 is important in both male (Chen et al. 2012) and female (Mak et al. 2016) germline development and in preventing neurodegeneration by repressing Ataxin1 expression (Gennarino et al. 2015), whereas Pum2 plays multiple roles in neuronal function (Vessey et al. 2006, 2010; Siemen et al. 2011; Driscoll et al. 2013). Moreover, both Pum1 and Pum2 are important for maintaining genomic integrity (Lee et al. 2016; Tichon et al. 2016). Despite these efforts, it remains unknown what role Pum 1 and Pum 2 play in neural development and what targets and mechanisms are mediated by them in the mammalian nervous system.

Among numerous RNA-binding proteins, one of the best studied in neurogenesis regulation is fragile $\mathrm{X}$ mental retardation protein (FMRP) - a translational repressor required for adult NSC proliferation and differentiation as well as hippocampal-dependent learning (Luo et al. 2010; Guo et al. 2011; Saffary and Xie 2011). Interestingly, Pum1 and Pum 2 have been identified as mRNA targets of FMRP in a RIP-chip (ribonucleoprotein immunoprecipitation followed by microarray) study (Brown et al. 2001) and HITS-CLIP (high-throughput sequencing of RNA isolated by cross-linking and immunoprecipitation) study in mouse brains (Darnell et al. 2011). What is more, Pum2 colocalizes with FMRP in the stress granules in neurons (Vessey et al. 2006), suggesting that there might be connections between Pum proteins and FMRP.

In this study, we demonstrate the neurogenic and cognitive function of Pum 1 and Pum 2 in mice. Furthermore, we identify mRNA targets of Pum1 and Pum2, which allow us to reveal multiple molecular pathways regulated by Pum 1 and Pum 2 in the brain. Finally, we report the interaction between Pum1, Pum2, and FMRP in neurogenesis.

\section{Results}

Pum1 and Pum2 are expressed in the cytoplasm of NSCs, progenitors, and neurons

To explore the function of Pum proteins in the mammalian brain, we first examined the expression of Pum 1 and Pum 2 in the mouse brain as compared with other nonneural tissues. Both Pum1 and Pum 2 mRNA transcripts are present in a variety of tissues, including brain, heart, kidney, liver, lung, muscle, skin, intestine, spleen, stomach, and thymus, as revealed by Northern blot hybridization (Spassov and Jurecic 2003a). To measure the developmental dynamics of the expression levels of Pum1 and Pum2 proteins in the brain, we performed immunoblotting at different developmental time points using whole-brain lysate at embryonic day 13.5 (E13.5) and microdissected hippocampus and cortex at postnatal day 1 (P1), P7, P15, P30, and $5 \mathrm{mo}$. The anti-Pum 1 and anti-Pum 2 antibodies that we used are specific to Pum1 and Pum2, respectively, in the brain for both Western blot and immunofluorescence, since we did not detect these proteins in neural-specific Pum1;Pum2 double conditional knockout mice (Supplemental Fig. S1C,D; see below). Both Pum1 and Pum2 are expressed at all of the above time points (Fig. 1A). Interestingly, the expression profiles of both Puml and Pum2 resemble that of neurogenesis, which occurs robustly from E11.5 to E18.5 and declines but continues to occur afterward. This indicates possible involvement of Pum1 and Pum2 in neurogenesis at both prenatal and postnatal periods.

In order to study in which cell populations Pum1 and Pum2 are expressed, we did coimmunofluorescence microscopy of Pum $1 / 2$-specific antibodies with different cell markers. SOX2 was used as a marker for NSCs, TBR2/ EOMES was used as a marker for neural progenitor cells (NPCs), and neuronal nuclei (NeuN) was used as a marker for mature neurons. We observed expression of both Pum 1 and Pum 2 in the cytoplasm of NSCs, NPCs, and mature neurons (Fig. 1B,C). To confirm the expression of the two proteins in the NSCs, we stained individual NSCs separated from cultured neurospheres with Pum $1 / 2$ and SOX2 antibodies. Pum1 and Pum 2 are indeed present in the cytoplasm of NSCs (Supplemental Fig. S1A,B). These results indicate the possibility that both proteins function throughout the entire course of neurogenesis.

Neural-specific double conditional knockout (Ndcko) of Pum1 and Pum2 results in defects in neurogenesis

Since Pum1 and Pum2 global double knockout mice are lethal by E8.5 (Uyhazi 2012), we generated neural-specific Pum1 and Pum2 double conditional knockout mice to study the role of Pum1 and Pum2 in neurogenesis. We crossed Pum1 and Pum2 double Flox mice (LoxP sites flanking exons 8 and 9 of Pum1 and exon 3 of Pum2) with Nestin promoter-driven Cre mice (Fig. 2A; Tronche et al. 1999). Nestin-Cre-mediated conditional knockout starts from the beginning of neurogenesis and occurs in the entire central nervous system by E15.5 (Dubois et al. 2006). We bred Pum ${ }^{+/ f}{ }_{i}$ Pum ${ }^{+/ f}{ }_{i}$ Nestin-Cre ${ }^{+}$with 

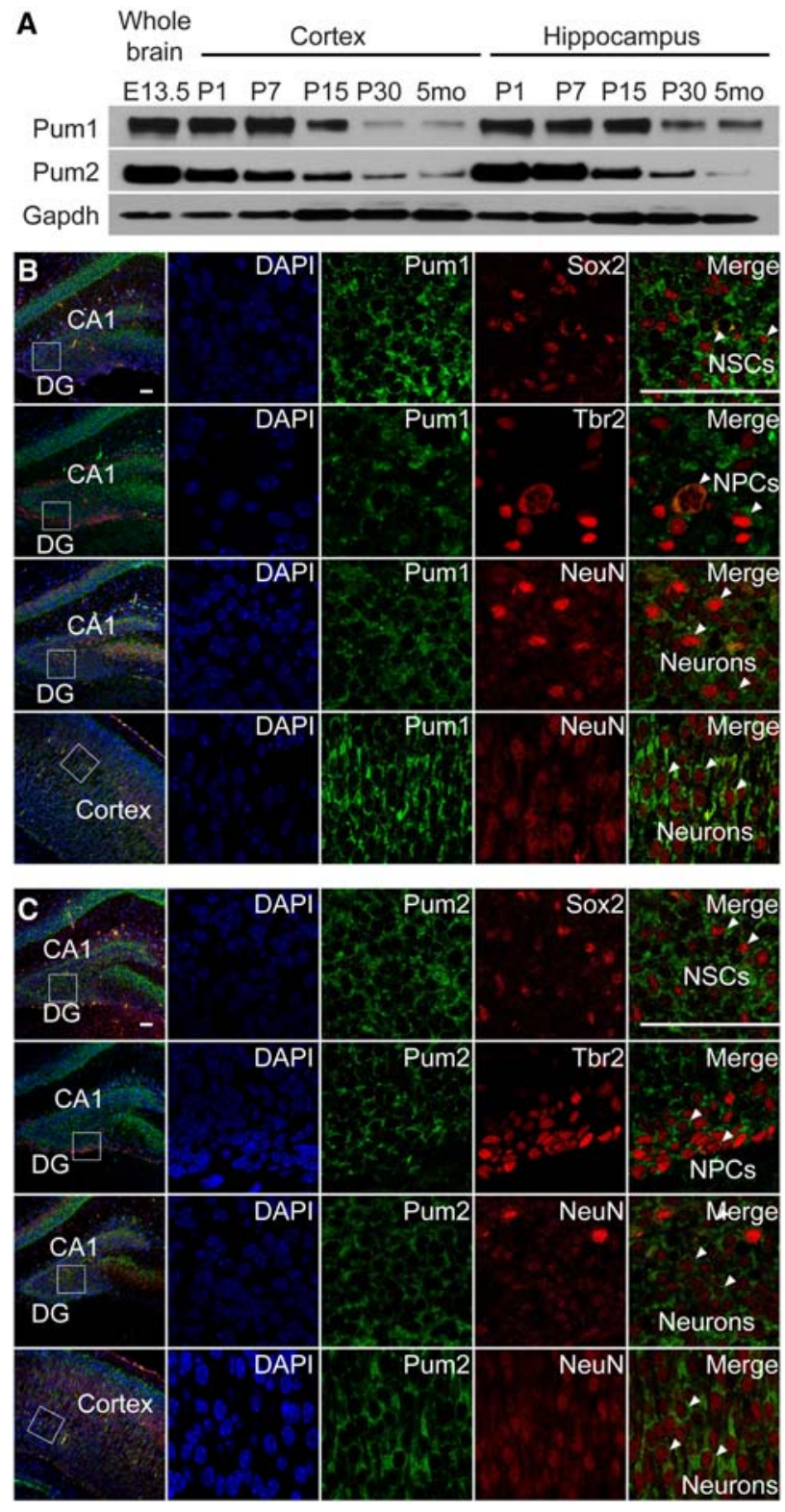

Figure 1. Pum 1 and Pum 2 are expressed in mouse brains. $(A)$ Western blot using lysate of whole brains at E13.5 and lysates of microdissected cortices and hippocampi at P1, P7, P15, P30, and 5 mo. (Pum1) 126 kDa; (Pum2) 114 kDa; (Gapdh) $37 \mathrm{kDa}$. $(B, C)$ Immunofluorescence of PUM1 $(B) /$ PUM2 $(C)$ and markers for NSCs (SOX2), neural progenitor cells (TBR2/EOMES), and neurons (neuronal nuclei [NeuN]). The right four columns are enlarged pictures of the boxed regions in the left column. White arrowheads point to representative cells with Pum $1 / 2$ localized in the cytoplasm of the marked cells. (Green) Pum1/Pum2; (red) SOX2/TBR2/NeuN; (blue) DAPI. Bar, $50 \mu \mathrm{m}$.

Pum $^{f / f}{ }_{;}$Pum2 $2^{f / f}{ }_{i}$ Nestin-Cre ${ }^{-}$in order to obtain control $\left(\right.$ Pum $^{+/ f}{ }_{;}$Pum $2^{+/ f}{ }_{i}$ Nestin-Cre $\left.{ }^{+}\right)$, Pum 1 conditional knockout $\left(\right.$ Pum $^{\text {flf }}{ }_{;}$Pum $2^{+/ f}{ }_{;}$Nestin-Cre $\left.{ }^{+}\right)$, Pum2 conditional knockout $\left(\right.$ Pum $^{+/} f_{;}$Pum $\left.2^{\text {flf }}{ }_{\text {iNestin-Cre }}\right)$, and Pum1 and Pum2 Ndcko $\left(\right.$ Pum $^{f / f}{ }_{;}$Pum $\left.^{f / f}{ }_{;} \mathrm{Nestin} \mathrm{Cre}^{+}\right)$mice as littermates. In the presence of Cre recombinase, exons 8 and 9 of Pum1 as well as exon 3 of Pum2 flanked by $\operatorname{Lox} P$ sites were deleted as shown by RNA sequencing (RNA-seq) (Fig. 2B) and resulted in a frameshift that leads to minimal protein expression (Fig. 2C,D) without any truncated protein residues (Supplemental Fig. S2A,B). The Ndcko mice are viable but smaller in size. They display a reduction in body weight (Supplemental Fig. S2C, D) and a proportional reduction in brain weight (Supplemental Fig. S2E,F). Hence, neural-specific depletion of Pum proteins does not affect viability but leads to reduced growth, possibly by compromising the hypothalamicadenohypophyseal axis of hormonal regulation.

Since the majority of the neurons in the mammalian forebrain is generated prenatally in the ventricular zone (VZ), SVZ, and DG (Rakic 1985; Gage 2000; Bhardwaj et al. 2006), we examined the Ndcko mouse DG. Strikingly,
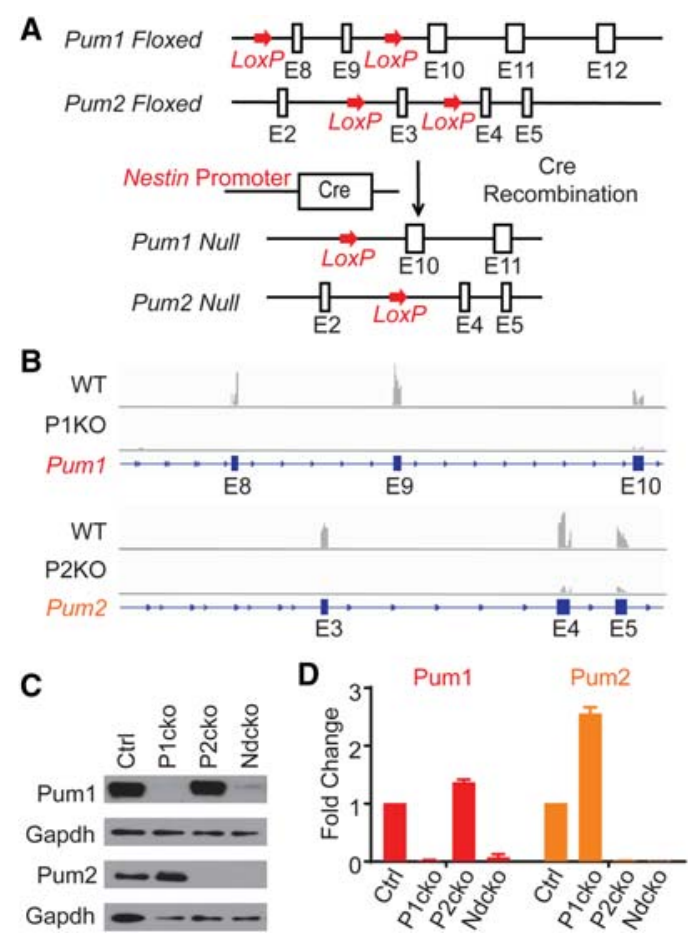

Figure 2. Nestin-Cre-mediated Pum1;Pum2 double-knockout animals. (A) Schematic diagram for the generation of NestinCre-mediated Pum1;Pum2 double-knockout mice. Exons 8 and 9 of the Pum1 allele and exon 3 of the Pum2 allele are flanked by Lox $P$ sites and depleted in the presence of Cre recombinase, resulting in null alleles. $(B)$ RNA-seq in neonatal brain lysates confirmed the depletion of exons 8 and 9 in the Pum 1 transcript in Pum1 global knockout (P1KO) mice and exon 3 in the Pum2 transcript in $\mathrm{P} 2 \mathrm{KO}$ mice. $(C)$ Highly efficient depletion of PUM1 and PUM2 protein from the nervous system in NestinCre-mediated conditional knockout mice as shown by Western blot using neonatal brain lysates. (Ctrl) Pum1 ${ }^{+/ f}{ }_{i} P_{\text {Pum2 }}{ }^{+/ f}$; Nestin-Cre ${ }_{;} ; \quad$ (P1cko) Pum1 ${ }^{f / f}{ }_{;}$Pum $^{+/ f}{ }_{;}$Nestin-Cre ${ }^{+} ;$(P2cko)

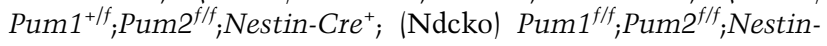
$\mathrm{Cre}^{+}$. (D) Quantification of the Western blot in $C$. The intensity of the Pum 1 and Pum 2 bands was normalized to the intensity of the respective Gapdh bands. For comparison, each data set was normalized to the control. $n=3$. 
we observed a significant reduction in size of the DG starting from neonatal day 1 to 12 mo of age (Fig. 3A; Supplemental Fig. S3A). Quantification of the DG volume using brain stereology revealed that there is an $\sim 60 \%$ reduction of the DG at P1, but, by P30, the mutant DG volume is further reduced to $<20 \%$ of the normal size and remains so during the subsequent $360 \mathrm{~d}$ of life (Fig. 3B). Even when normalized to the brain weight (which is an underestimate of DG reduction because the reduced brain weight is partly due to reduced DG), the reduction is still highly significant (Fig. 3C). In contrast, the measurement of the area of the CA1 (cornu ammonis region 1) stratum and pyramidal cell layer did not reveal any significant differences between the control and Ndcko mice at neonatal and adult stages (Fig. 3D), indicating that the size reduction is specific to the DG region that contain NSCs. Our finding of the reduced DG suggests that Pum proteins might be critical for learning and memory because neurogenesis in the DG generates new neurons for the hippocampus, which is the learning and memory center in mammals.

We then compared neurogenesis between control and Ndcko brain sections. Neurogenesis in the hippocampus originates with NSCs, which give rise to early progenitor cells that then differentiate into immature neurons and finally mature neurons (Fig. 3E). We used TBR2/EOMES as an early progenitor cell marker and Doublecortin (DCX) as an immature neuron marker. Since the DG area is reduced in the Ndcko brain, we normalized the number of positively stained cells to the corresponding DG area to estimate the relative cell density. As compared with the control, the Ndcko brain had a much higher density of TBR2 ${ }^{+}$NPCs (Fig. 3F,G; Supplemental Fig. S3B) but much lower density of $\mathrm{DCX}^{+}$immature neurons (Fig. 3H,I; Supplemental Fig. S3C), indicating that depletion of Pum1 and Pum2 leads to a shift in the cell composition during neurogenesis, with an accumulation of NPCs but a reduction of immature neurons. We also examined the proliferation of the NSCs by costaining of Sox 2 and BrdU after $30 \mathrm{~min}$ of labeling. We did not find a significant difference in the ratio of BrdU-positive cells to Sox2-positive cells between the control and Ndcko mice (Supplemental Fig. S4C,D). Besides the neurogenesis lineage, we also compared the ratio of astrocytes and neurons by costaining GFAP (glial fibrillary acidic protein) and NeuN and immunoblotting of GFAP using control and Ndcko neonatal brains, which showed that there might be an increased ratio of astrocytes/neurons in Ndcko mice (Supplemental Fig. S4A,B). Furthermore, we found that the neonatal Ndcko mouse brains displayed drastically increased apoptosis in the DG compared with their littermate controls (Fig. 3J,K) but not at later stages (Supplemental Fig. S3D). This finding echoes our laboratory's previous study of Pum1 in mouse spermatogenesis, where Pum1 suppresses apoptosis of spermatocytes (Chen et al. 2012). Costaining of Caspase 3 with Sox2 (Supplemental Fig. S4E), Tbr2 (Supplemental Fig. S4F), or NeuN (Supplemental Fig. S4G) indicates that neurons are most likely the type of cell that undergoes apoptosis.
Deletion of Pum1 and Pum2 leads to reduced self-renewal and compromised differentiation of neural stem and progenitor cells (NSPCs)

To further study the functions of Pum proteins in neurogenesis, we compared the control and Ndcko NSPCs using a neurosphere assay (Fig. 4A). NSPCs from the control and Ndcko DG gave rise to primary neurospheres starting from day 4 of culture in neurosphere medium. At day 7 , we counted the number of primary neurospheres $(\geq 30$ $\mu \mathrm{m}$ in diameter) as an indicator of the number of NSPCs. The neurospheres were then passaged every week, and the number of viable cells was recorded at every passage to estimate the self-renewing division ability of NSPCs. We observed that the Ndcko NSPCs formed much fewer and much smaller primary neurospheres compared with those isolated from control mice (Fig. 4B; Supplemental Fig. S5A,C), indicating that there were fewer self-renewing NSPCs in the Ndcko DG. Furthermore, the neurosphere-forming NSPCs isolated from Ndcko mice did not further divide and displayed significantly lower viability as compared with the control NSPCs (Fig. 4C, D), indicating a significant reduction in self-renewing division.

To further investigate the self-renewing ability of Ndcko NSPCs, we digested the primary neurospheres and plated 5000 cells for secondary neurosphere formation. Seven days after plating, the neurospheres were counted and then cytospun for TUNEL assay and BrdU staining (after $24 \mathrm{~h}$ of labeling). Ndcko NSPCs gave rise to much fewer secondary neurospheres with much more reduced sizes (Fig. 4B; Supplemental Fig. S5B,D). Furthermore, the formed neurospheres displayed much increased apoptosis (Fig. 4E) and decreased proliferation (Fig. 4F), indicating a compromised ability of the mutant NSPCs in self-renewing divisions.

To test the differentiation ability of NSPCs, we plated the same number of control and Ndcko NSPCs in differentiation medium and observed their differentiation after 10 $\mathrm{d}$ of culture. The Ndcko NSPCs differentiated into fewer neurons ( $\beta$-tubulin $\mathrm{III}^{+}$) than the control NSPCs (Fig. 4G). Together, the results in this section indicate that the Ndcko DG has a significantly reduced number of active NSPCs and that the mutant stem cells show defects in both maintenance and differentiation in vitro. Both observations resemble the in vivo phenotype of the Ndcko mice.

\section{Ndcko mice display defects in learning and memory}

Because the depletion of Pum1 and Pum2 from the nervous system leads to pleiotropic defects in the DG, we hypothesized that spatial learning and long-term memory, for which hippocampal neurons are critical, would be adversely affected. We assessed the learning and memory in both young (4- to 6-mo-old) and aged (12-mo-old) Ndcko mice using a low-stress cognitive test: the Lashley III maze (Fig. 5A; Bressler et al. 2010). Each mouse was subjected to one trial in the maze per day for 15 consecutive days. Young Ndcko mice took a longer time than their 

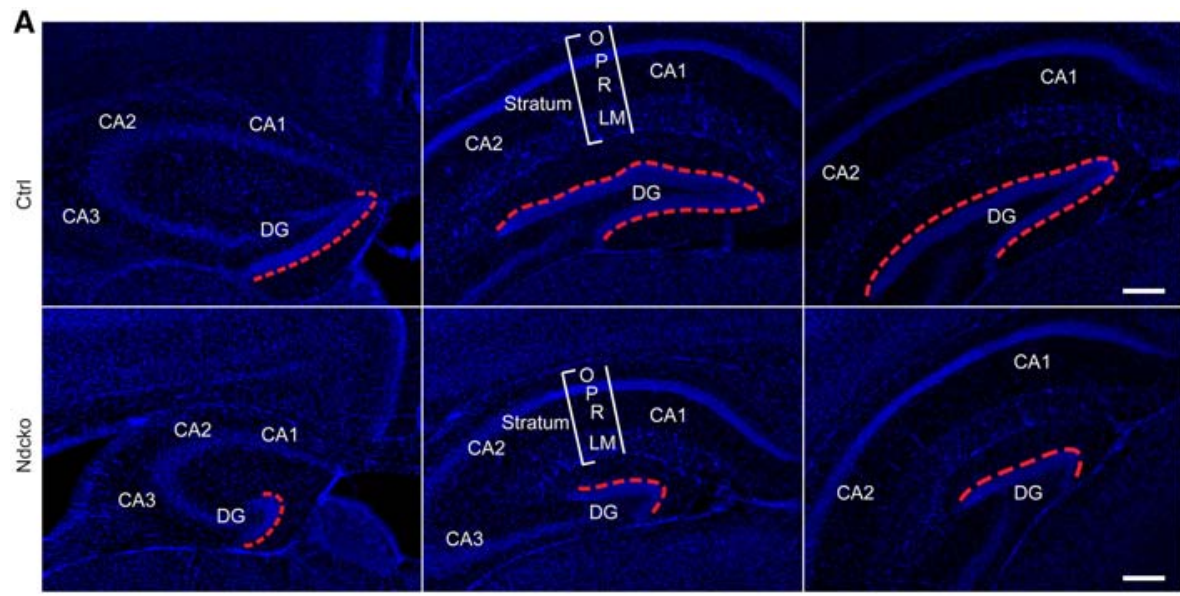

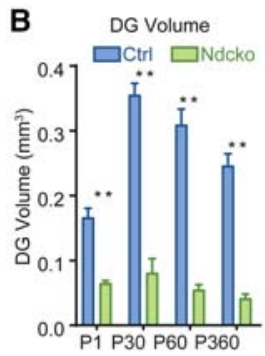

C DG Volume
Normalized to Brain Weight

D CA1 Area $2.01 \quad \square$ Ctrl
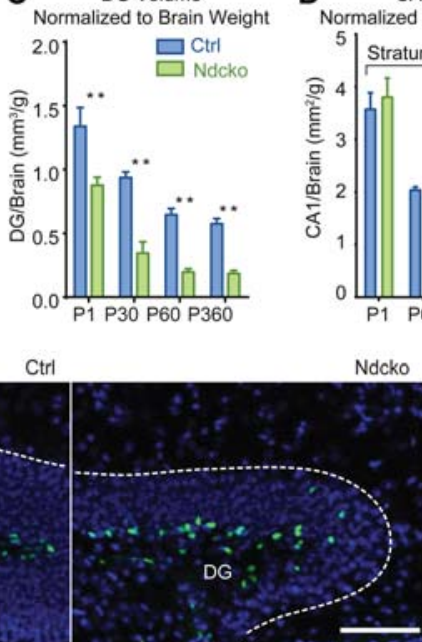

Ctrl

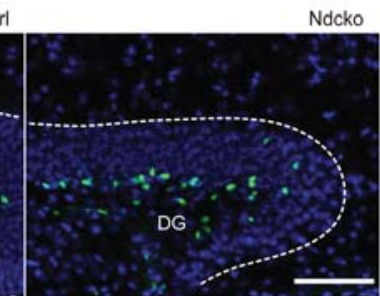

Ndcko

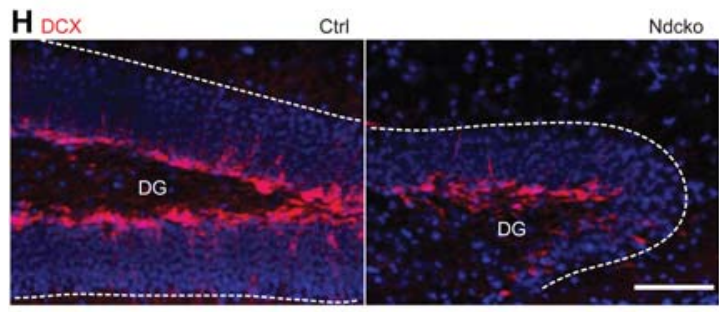

Ctri
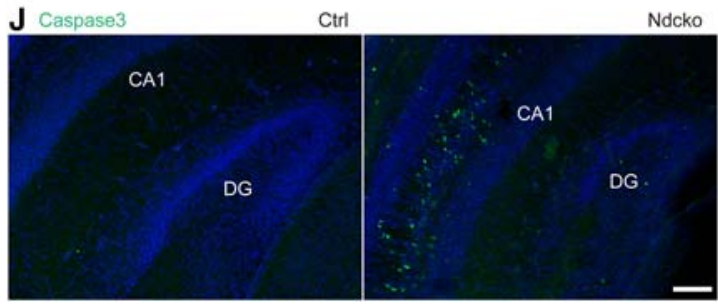

Ndcko
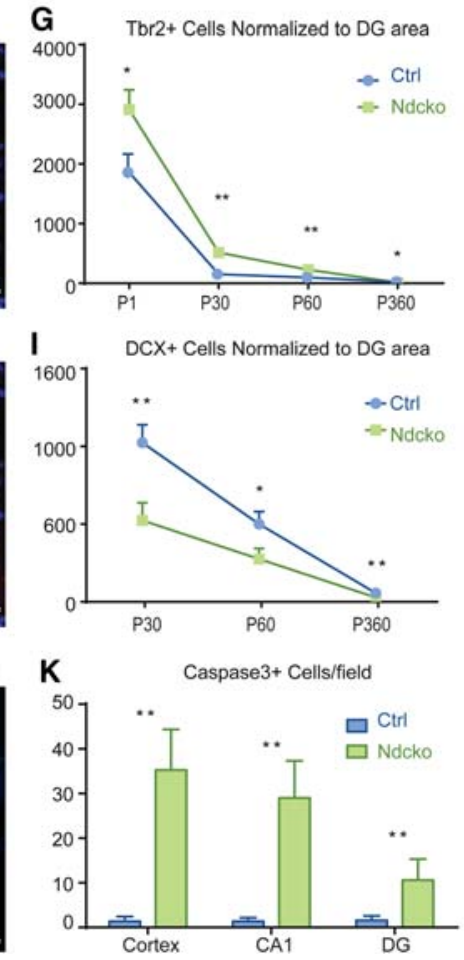

Figure 3. Depletion of Pum1 and Pum2 resulted in neurogenesis deficiency. (A) Representative images of P60 control and Ndcko brain coronal sections. The horizontal check mark-shaped dense granule cell zones defined by red dotted lines are the DG. (Left to right) Anterior to posterior. $(\mathrm{O})$ Statum oriens; $(\mathrm{P})$ pyrimidal cell layer; $(\mathrm{R})$ stratum radiatum; (LM) lacunosum molecular; (blue) DAPI. Bar, 100 $\mu \mathrm{m} .(B, C)$ Quantification of the absolute DG volume $(B)$ and the DG volume normalized to the corresponding brain weight $(C)$ in control and Ndcko mice at different time points. $\left.{ }^{* *}\right) P$-value $<0.01 . n=4-6$. $(D)$ Quantification of the whole stratum layer and the pyramidal cell layer area of the CA1 (cornu ammonis region 1) region normalized to the corresponding brain weight in control and Ndcko mice at P1 and P60 as representative time points. $n=4-6$. (E) Illustration of cell lineage during neurogenesis: NSCs give rise to NPCs, which eventually differentiate into neurons. $(F, H)$ Representative TBR2 $(F)$ and Doublecortin (DCX) $(H)$ staining on P30 control and Ndcko brains. The white dotted line defines the DG. (Green) TBR2; (red) DCX; (blue) DAPI. Bar, $100 \mu \mathrm{m}$. (G,I) Quantification of TBR2-positive and DCXpositive cells normalized to the DG area at different time points. For each animal, four to six serial sections of the brain were scored and averaged. $\left(^{*}\right) P$-value $\left.<0.05 ;{ }^{* *}\right) P$-value $<0.01 . n=4-6$. $(J, K)$ Increased apoptosis in neonatal Ndcko brains compared with control in the cortex and hippocampus. (Green) Activated Caspase3; (blue) DAPI. Bar, $100 \mu \mathrm{m}$. $\left(^{* *}\right.$ ) $P$-value $<0.01 . n=5$. 


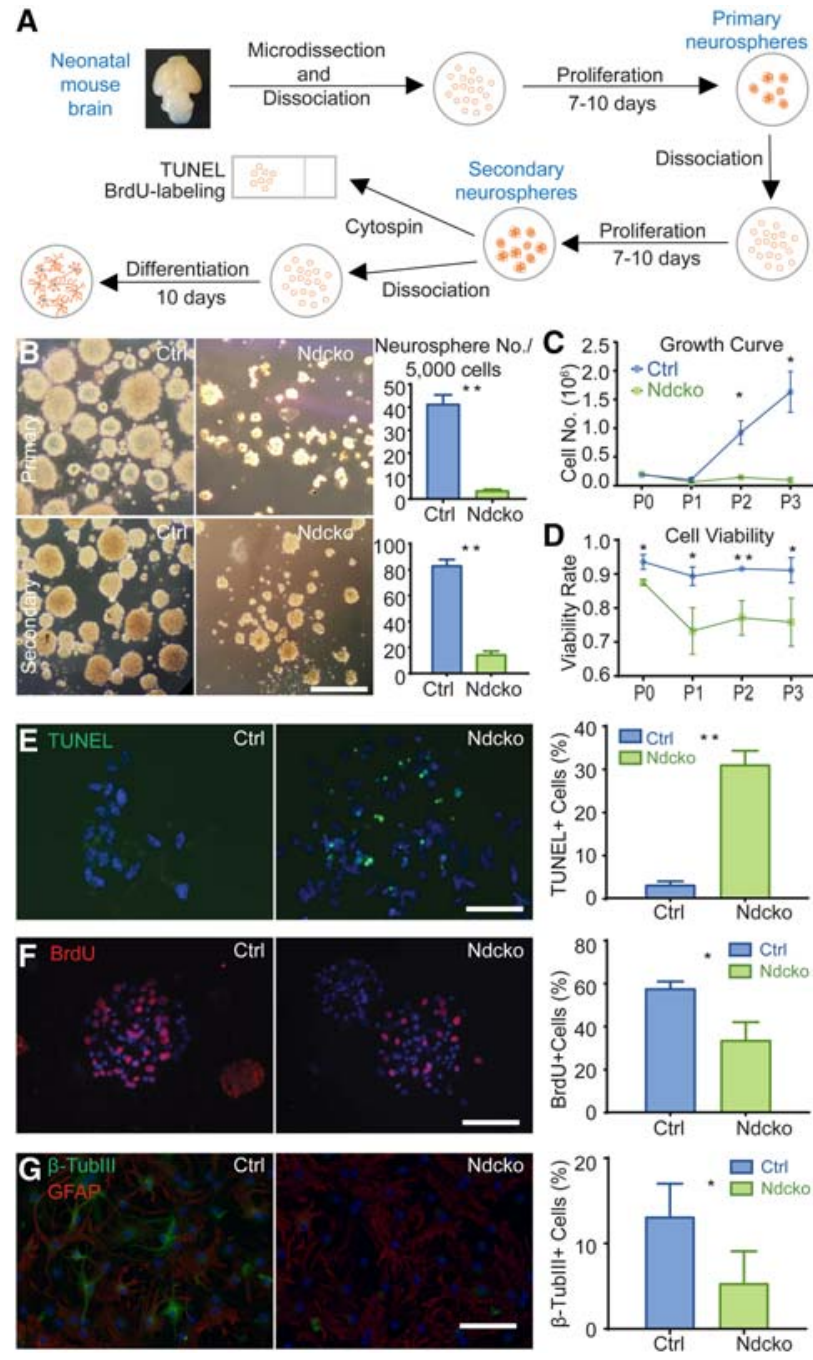

Figure 4. Ndcko NSPCs are deficient in self-renewal and differentiation. (A) Experimental procedure of neurosphere assays. (B) Representative images and quantification of primary and secondary neurospheres from control and Ndcko NSPCs. Bar, $0.1 \mathrm{~mm}$. $(* *) P$-value $<0.01 . n=5$. $(C, D)$ Growth curve $(C)$ and cell viability $(D)$ of the cultured NSPCs based on the total cell numbers $(C)$ and Trypan blue staining-negative cell numbers divided by total cell numbers $(D)$ prior to seeding the cells at P0 (harvest day), P1 (passage 1), P2, and P3. $\left(^{*}\right) P$-value $<0.05 . n=5$. (E) Apoptosis in control and Ndcko neurospheres by TUNEL staining. (Green) TUNEL; (blue) DAPI. Bar, $100 \mu \mathrm{m}$. $\left(^{* *}\right) P$-value $<0.01 . n=3 .(F)$ Proliferation in control and Ndcko neurospheres by $24 \mathrm{~h}$ of BrdU labeling. (Red) BrdU; (blue) DAPI. Bar, $100 \mu \mathrm{m}$. (*) $P$-value $<0.05 . n=3$. $(G)$ Differentiation of control and Ndcko NSPCs into neurons and astrocytes. (Green) $\beta$-tubulin III ( $\beta$-TubIII); (red) GFAP; (blue) DAPI. Bar, $100 \mu \mathrm{m} .\left(^{*}\right) P$-value $<0.05 . n=3$.

control siblings to learn the maze (Fig. 5B). In the aged cohorts, all of the control mice learned the maze within 6-10 $\mathrm{d}$, while none of the aged Ndcko mice learned the maze by the end of $15 \mathrm{~d}$ (Fig. 5B).

To further quantify the ability of learning, we used the learning index - the ratio of correct entries to total entries - as an indicator of learning. On the first trial, all of the animals randomly explored the maze, and thus the learning index was $\sim 0.5$; in the subsequent trials, both the young and old the control animals increasingly made more correct entries and fewer errors, leading to an increase in the learning index (Fig. 5C,D). In contrast, both young and aged Ndcko mice essentially were unable to learn the maze; thus, the learning index of the Ndcko mice did not increase during the first $4 \mathrm{~d}$ (Fig. 5C,D). We quantified the difference in the rate of learning by comparing the change in the learning index per day between the age-matched control and Ndcko mice. This comparison revealed that both young and old Ndcko mice were more than sevenfold slower than their aged-matched control mice in learning (Fig. 5E). These analyses indicate that Pum proteins in the nervous system are important for learning and memory, which may be due to their effects on neuronal differentiation and survival.

\section{Individual nucleotide resolution CLIP (iCLIP) revealed many Pum1 and Pum2 target genes and their binding sites}

To unravel the molecular mechanisms mediated by Pum 1 and Pum2, we performed iCLIP to identify Pum1 and Pum2 target RNAs and delineate the Pum-binding sites at the single-nucleotide resolution. We used neonatal wild-type brains for Pum1 and Pum2 iCLIP, with neonatal brains from Pum1 global knockout (P1KO) and P2KO mice as the negative controls, respectively (Supplemental Fig. S6A-D). Three biological replicates were carried out
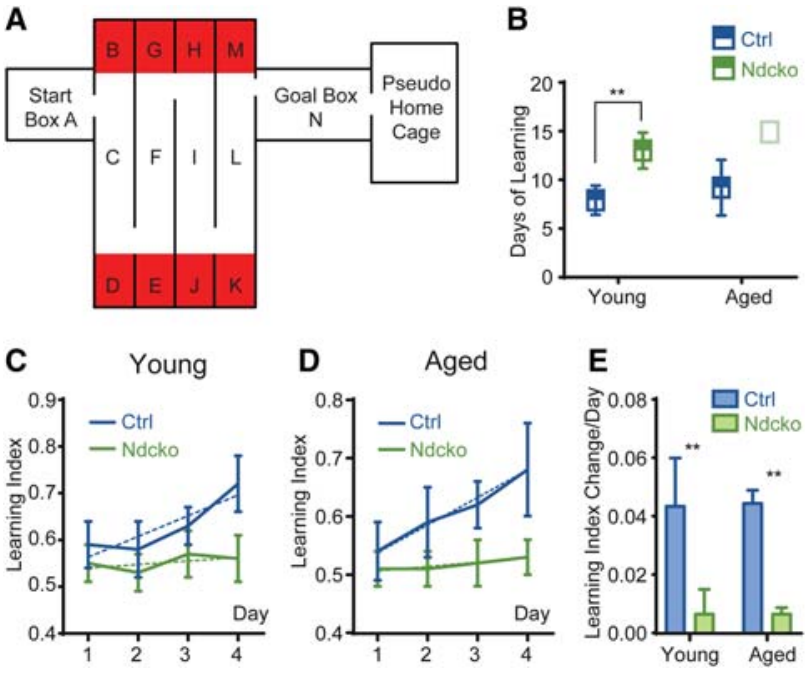

Figure 5. Ndcko mice have impaired learning and memory. $(A)$ Schematic diagram of the Lashley maze. $(B)$ Days of learning for young (4- to 6-mo-old) and aged (12- to 14-mo-old) cohorts of control and Ndcko animals. None of the aged Ndcko mice learned the maze by the end of the 15-d test. $(C, D)$ The learning index (correct entries/total entries) on the first four test days for young $(C)$ and aged $(D)$ control and Ndcko animals. Dotted lines represent the linear regression of each data set. $(E)$ The slopes of the learning index linear regression from $C$ and $D$. $\left(^{* *}\right) P$-value < 0.01. $n=6$ for young groups; $n=9$ for aged groups. 
for each condition (Supplemental Table S1). All replicates showed large overlaps for Pum1- and Pum2-binding genes (Fig. 6A).
We calculated the Spearman correlation of genes across the replicates in each condition. As indicated by heat maps in Supplemental Figure S7, all $r$-values of wild-
A

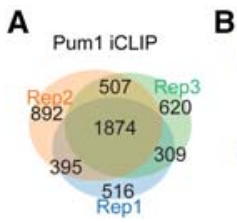

Pum2 iCLIP

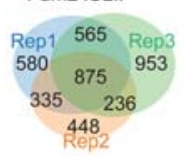

D Pum1 iCLIP

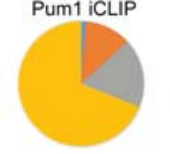

G B Biological Process Pum1 icLIP

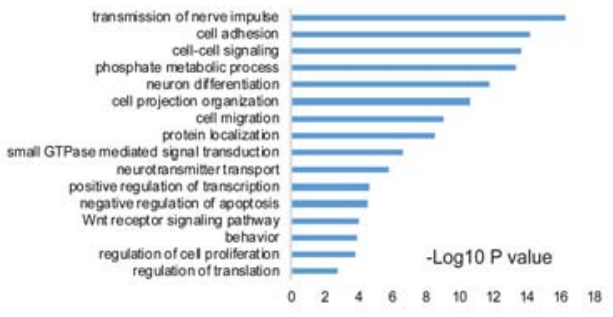

I

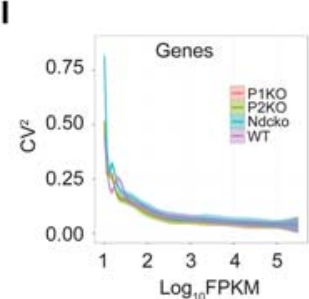

$\mathbf{J}_{\text {Color Key }}$
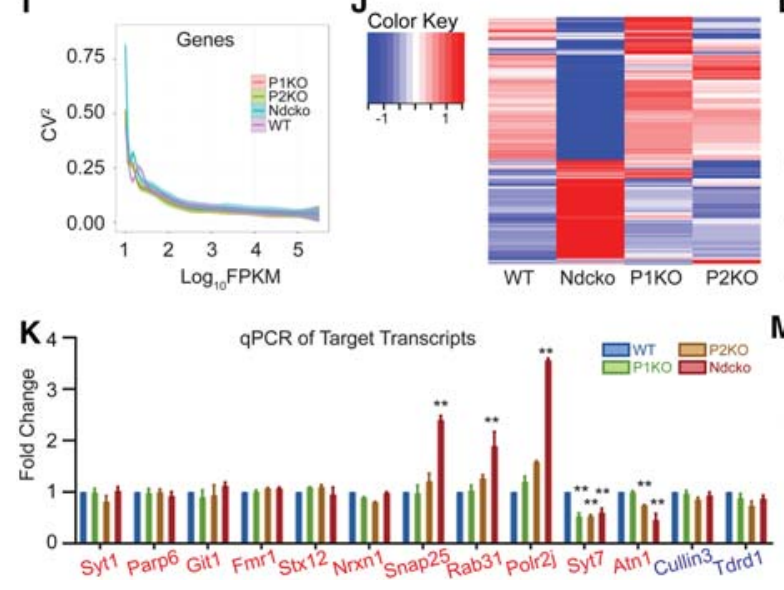

WT-Pum1 [0-10]

$\mathbf{H}$

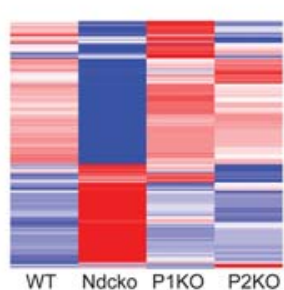

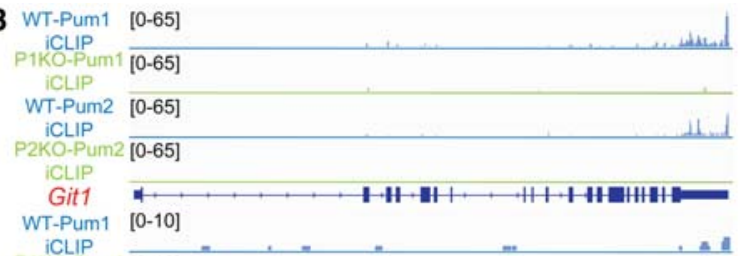

ICLIP
WT-Pum2

iCLIP

iCLIP

PUm2 ICLIP $=3$ JUTR

IIUTR

intron

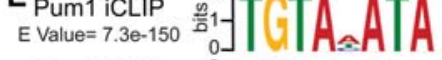

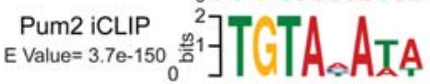
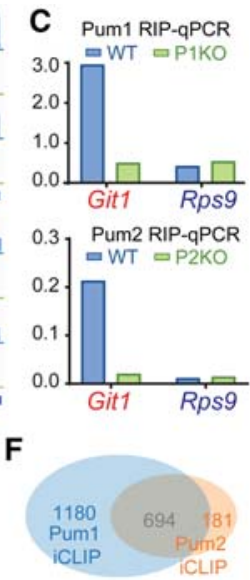

Biological Process Pum2 iCLIP
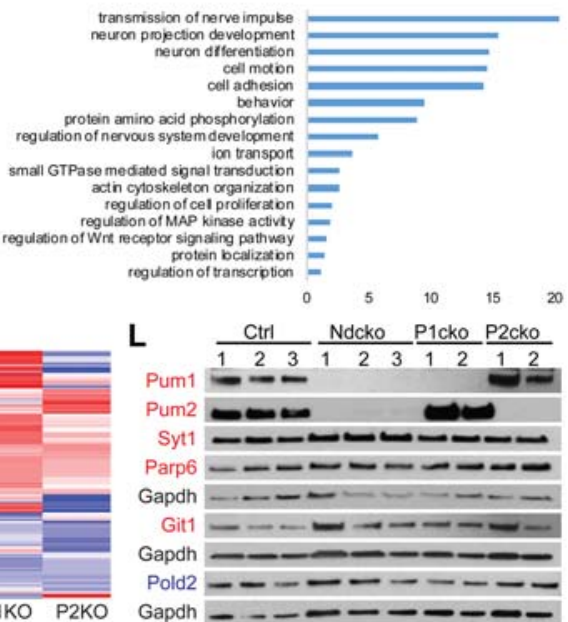

Gapdh $-\ldots---1$

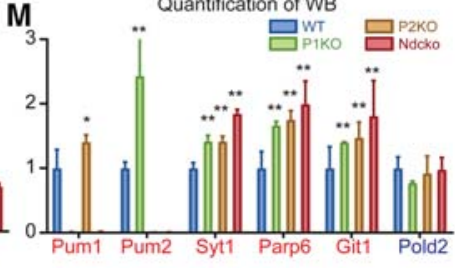

Figure 6. iCLIP-seq (iCLIP combined with high-throughput sequencing) identification of Pum1 and Pum2 targets. (A) Reproducibility among biological triplicates for Pum1 and Pum2 iCLIP, indicated by significant overlapping of the binding site-associated genes. (Rep) Biological repeat (the numbers of genes are indicated). (B) iCLIP peaks on the Git1 and Rps9 transcript in Pum1 iCLIP and Pum2 iCLIP. Git1 is a target for Pum1 and Pum2, and Rps9 is a nontarget. (C) Pum1 and Pum2 RIP-qPCR validation of the target Git1 and nontarget Rps9. (D) Distribution of the Pum1-binding sites (left) and Pum2-binding sites (right) in different genomic sections. (E) MEME results for de novo discovery of the binding motif for Pum1 (top) and Pum2 (bottom). (F) Comparison between Pum1 and Pum2 target genes. Pum 1 has 1874 target genes, and Pum 2 has 875 target genes, 694 of which are common targets. $(G, H)$ Biological processes identified by gene ontology analysis of Pum $1(G)$ and Pum $2(H)$ target genes. $(I)$ Reproducibility among biological repeats for RNA-seq, indicated by the coefficient of variation. (Four repeats for wild type, $\mathrm{P} 1 \mathrm{KO}$, and $\mathrm{P} 2 \mathrm{KO}$ and three repeats for Ndcko). (J) RNA-seq heat map showing the expression of the 694 iCLIP-identified Pum 1 and Pum 2 common target transcripts in wild type, Ndcko, P2KO, and P1KO. (K) RT-qPCR analysis of iCLIP-identified Pum 1 and Pum 2 common targets in wild type, Ndcko, P2KO, and P1KO. (Red) Targets; (blue) nontargets. Data were normalized to Ubqln1. $n=3$. $(L)$ Western blot analysis of iCLIP-identified Pum1 and Pum 2 common targets revealed regulation of these targets at the protein level. (Red) Targets; (blue) nontargets; (black) loading control. (M) Quantification of the Western blot in L. Gapdh bands or prestained gels (Supplemental Fig. S6G) were used for normalization. For each protein, the results were normalized to wild type. $\left({ }^{*}\right) P$-value $<0.05 ;\left({ }^{* *}\right) P$-value $<0.01 . n=9$. 
type samples are $>0.88$, showing a good reproducibility of the replicates. In addition, we recovered previously reported Pum targets such as Pum1 and Pum2 (Supplemental Table S2). Furthermore, we validated some of the iCLIPidentified targets by Pum1 and Pum2 RIP-qPCR using the same materials (Fig. 6B,C; Supplemental Fig. S6E,F). Together, these results indicate the good quality of our iCLIP data.

In our iCLIP analysis, we identified the binding sites for Pum1 and Pum 2 as cross-linking-induced truncation sites (CITS) using the publicly available software developed by the Zhang laboratory (Moore et al. 2014). To gain the information about Pum1's and Pum2's binding preferences, we normalized the number of binding sites in each genomic segment to the segment length and found that both Pum1 and Pum2 were preferentially bound to the $3^{\prime}$ UTRs of the mRNAs, with the second abundant region being the 5' UTR (Fig. 6D).

The motifs that we discovered for both Pum 1 and Pum 2 are identical to the conserved binding motif UGUAHAUA (H represents A/C/U) (Fig. 6E). More specifically, 408 of 3393 Pum1-binding sites and 317 of 1068 Pum2binding sites contain known Pum-binding motifs (Supplemental Table S2). Moreover, most of the motif-containing sites reside in the $3^{\prime}$ UTRs of transcripts, with 372 out of $408(91 \%)$ for Pum1 sites and 289 out of 317 (91\%) for Pum2 sites. This indicates that the Pum protein family preferentially binds to 3' UTRs (Supplemental Table S2).

The Pum1-binding genes and the Pum2-binding genes share 694 common targets (Fig. 6F). Gene ontology (GO) analysis of the targets for Pum1 and Pum2 showed similar results. The top pathways that are enriched in Pum targets include cell adhesion, cell migration, synapse function, neuron differentiation, and development as well as other pathways that are critical for neurogenesis (Fig. 6G,H). From the targets, we speculate that Pum proteins regulate multiple cellular pathways to achieve their neural function in both maintaining NSCs at early stages and ensuring proper neuron differentiation at later stages.

\section{Pum1 and Pum2 regulate their target mRNAs mainly at the post-transcriptional level}

To investigate how Pum1 and Pum 2 regulate their targets, we measured the expression level of their targets at the RNA and protein levels. First, we used one-tenth of the samples from the Pum1 and Pum2 iCLIP experiments (four biological repeats of wild-type, P1KO, and P2KO neonatal brains) to extract total RNA for RNA deep sequencing. We also collected three Ndcko neonatal brains for RNA deep sequencing. The coefficient of variation showed high reproducibility among the three or four biological repeats for each condition (Fig. 6I). P1KO and P2KO showed only $\sim 100$ and $\sim 300$ differential expressed genes compared with wild type. However, the Ndcko mutant showed >7000 differentially expressed genes compared with wild type. We then plotted the heat map using iCLIP-identified Pum 1 and Pum 2 common targets. We found that only a small number of the 694 common targets showed differential expression in P1KO or $\mathrm{P} 2 \mathrm{KO}$ as compared with wild type. However, 370 of the common targets showed differential expression in Ndcko brains as compared with wild type, with 211 targets down-regulated and 159 targets up-regulated (Fig. 6J).

To further relate the function of Pum proteins to the DG, we analyzed those of the 694 common target genes that are expressed in the DG. A recent RNA-seq study identified 7499 genes that are expressed in specific cell types of the DG (Cembrowski et al. 2016). We found that 563 out of the 694 common target genes are among the 7499 genes expressed in the DG, while 908 out of 1180 Pum1-exclusive targets and 137 out of 181 Pum2-exclusive targets are expressed in the DG, indicating that Pum1 and Pum 2 mostly target the DG transcripts.

We then further analyzed 416 neuron-enriched genes as reported by a previous study that profiled mRNA-seq from specific types of brain cells (Zhang et al. 2014). Among these neuron-enriched genes, there are 108 up-regulated and 130 down-regulated genes in Ndcko as compared with wild type. For example, neuron-specific gene Rbfox3 $(\mathrm{NeuN})$ is 1.9-fold down-regulated in the Ndcko as compared with Pum1 wild type (Supplemental Tables S3, S4), suggesting that Ndcko has an impact on neuron-enriched genes. Among these neuron-enriched genes, 210 are expressed in the DG, with 59 up-regulated and 67 down-regulated genes in Ndcko as compared with wild type, again indicating the DG as the main target area for Pum $1 / 2$ regulation among neuron-enriched genes. qRTPCR using RNA extracted from neonatal brains validated the RNA-seq data (Fig. 6K). These results indicate that Pum1 and Pum2 together, but not alone, have an impact on the levels of a subset of their mRNA targets, possibly by regulating their stability. Meanwhile, most of the differentially expressed genes in Ndcko are more likely to be due to indirect effects resulting from depletion of both Pum1 and Pum2.

To determine whether Pum1 and Pum2 regulate their targets at the protein level, we selected a few targets that are present in the multiple GO-enriched pathways and critical for neurogenesis and measured their protein levels by immunoblotting. All of the examined targets showed up-regulation in P1KO, P2KO, and Ndcko (Fig. 6L,M; Supplemental Fig. S6G), indicating that Pum1 and Pum2 (either alone or together) repress the translation of these targets.

\section{Pum1 and Pum2 interact with FMRP in an RNA- dependent manner}

Our analysis of the 694 common targets shared by Pum 1 and Pum 2 revealed that 200 of them are also HITS-CLIP targets of FMRP, another important translational regulator of neurogenesis (Fig. 7A; Darnell et al. 2011). FMRP is encoded by the Fmr1 gene on the $\mathrm{X}$ chromosome whose mutation is associated with the fragile $\mathrm{X}$ syndrome. Our iCLIP experiments also identified Fmr1 mRNA as a common target of Pum1 and Pum2 (Supplemental Fig. S8A). Previous studies have shown that depletion of FMRP from NSCs leads to altered hippocampal neurogenesis and defects in hippocampus-dependent learning (Guo 
A
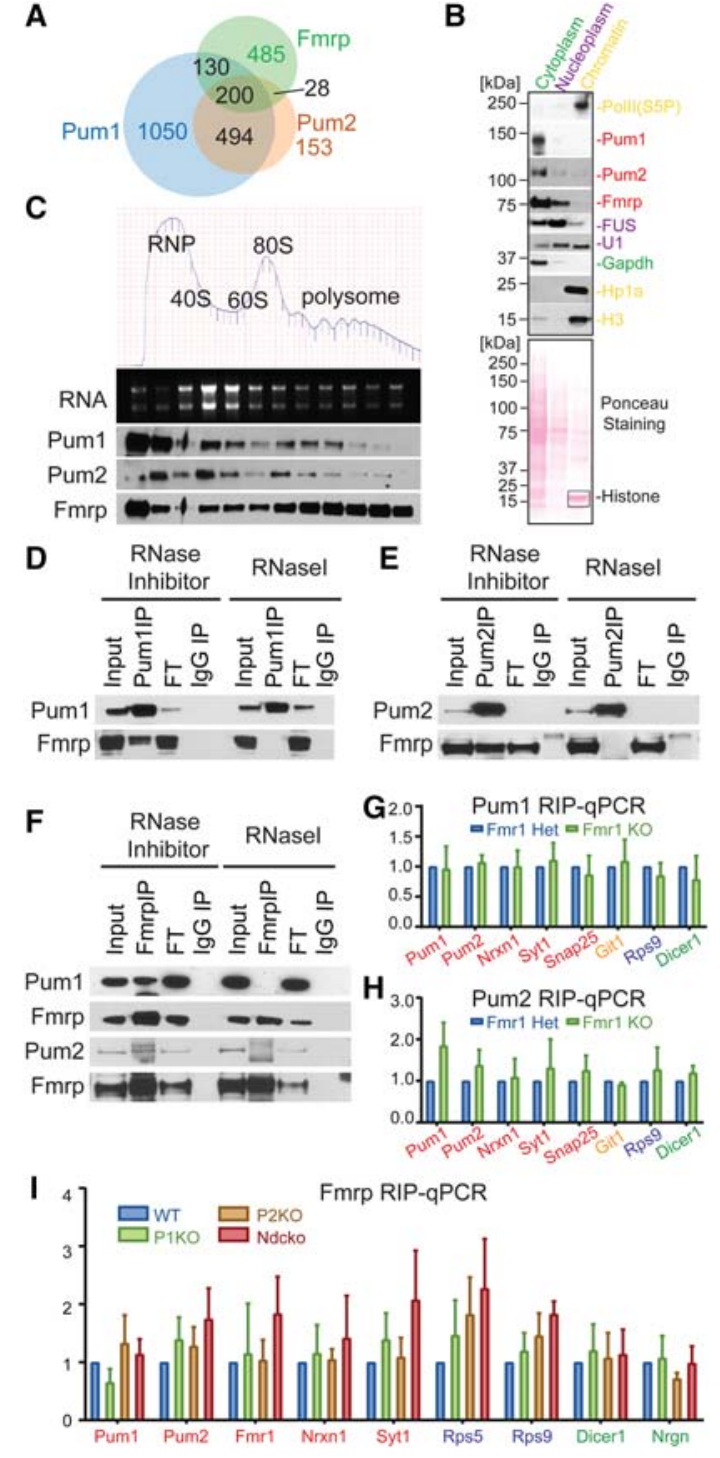

Figure 7. Pum proteins interact with Fmrp in an RNA-dependent manner. (A) Venn diagram of Pum1 iCLIP-identified, Pum2 iCLIP-identified, and Fmrp HITS-CLIP-identified (Darnell et al. 2011) target genes. (B) Fraction of a wild-type neonatal mouse brain into cytoplasmic, nucleoplasmic, and chromatin compartments. The proteins used as markers are color-coded with the corresponding compartments. $(C)$ Polysome fractionation of wild-type neonatal mouse brains. Every third fraction was used for RNA and protein analysis. $(D-F)$ Immunoprecipitation of Pum1 $(D)$, Pum2 $(E)$, and Fmrp $(F)$. (FT) Flow-through. (G, $H$ ) Pum1 $(G)$ and Pum2 $(H)$ RIP in Fmr1 heterozygous (Het) and homozygous knockout (KO) neonatal brains. RT-qPCR was used to analyze the immunoprecipitation/input enrichment of the Pum1, Pum2, and Fmrp common targets (red); Pum-unique target (yellow); Fmrp-unique target (green); and nontarget (blue) in the knockout compared with heterozygous. Two biological repeats, each with two technical repeats. (I) Fmrp RIP in wild-type, P1KO, P2KO, and Ndcko neonatal brains. RT-qPCR was used to analyze the immunoprecipitation/input enrichment of the Pum1, Pum2, and Fmrp common targets (red); Fmrp-unique targets (green); and nontargetd (blue) in the mutants compared with wild type. Three biological repeats, each with two technical repeats. et al. 2011) - a phenotype very similar to that of the Pum Ndcko mice. Moreover, both Pum 1 and Pum 2 mRNAs were FMRP targets, as identified as by HITS-CLIP. These important connections led us to study the functional relationship between FMRP, Pum1, and Pum2 in regulating neurogenesis.

We first examined whether Pum1, Pum2, and FMRP are in the same cellular compartments. We performed cellular fraction to separate the cytoplasm, nucleoplasm, and chromatin and used immunoblotting to detect the localization of Pum1, Pum2, and FMRP. We found that both Pum1 and Pum2 are localized almost exclusively in the cytoplasm and that the majority of FMRP is also localized in the cytoplasm (Fig. 7B). We then used polysome fractionation to examine the presence of Pum1, Pum2, and Fmrp in the polysomes and found that Pum proteins and FMRP broadly cofractionate in RNP, ribosomal subunits, and monosome and polysome fractions (Fig. 7C). We also performed highperformance liquid chromatography (HPLC) on neonatal mouse brain lysates to separate protein complexes based on size and found that Pum1, Pum2, and FMRP comigrated in similar profiles (Supplemental Fig. S8B). To analyze whether this comigration reflects the presence of these proteins in the same complexes, we immunoprecipitated FMRP, Pum1, and Pum2 individually from protein extracts of neonatal mouse brains and examined whether the other two proteins were coimmunoprecipitated. Indeed, FMRP coimmunoprecipitated with both Pum1 and Pum2 (Fig. 7D,E). Reciprocal coimmunoprecipitation using anti-FMRP antibodies confirmed the interaction (Fig. $7 F$ ), indicating that FMRP indeed forms a protein complex with Pum1 and Pum2. However, the interaction was disrupted when the samples were treated with RNasel (Fig. 7D-F), indicating that the interaction between FMRP and Pum proteins is RNA-dependent.

To investigate the impact of Pum 1 and Pum 2 on FMRP binding to its targets, we performed Pum1 and Pum2 RIP from Fmr1 heterozygous and homozygous knockout brains (Fig. 7G,H) and, reciprocally, FMRP RIP from wild-type, P1KO, P2KO, and Ndcko mouse brains (Fig. 7I). We selected a few Pum1, Pum2, and FMRP common targets as well as FMRP-unique targets and examined their enrichment in the FMRP/Pum1/Pum2 RIP using qRT-PCR. We found that depletion of Pum or FMRP did not significantly impact their binding to their common targets, suggesting that Pum and FMRP do not affect each other's binding to their target mRNAs but might be involved in exerting the regulatory effect of each other toward their target mRNAs.

\section{Discussion}

\section{Pum1 and Pum2 play crucial roles in hippocampal neurogenesis and function}

PUF proteins are highly conserved for their defining structure (the C-terminal RNA-binding domain) and their UGUAHAUA-binding motif from yeasts to humans (Wickens et al. 2002; Keene 2007; Quenault et al. 2011; Chen et al. 2012), but their function in stem cell 
maintenance has been demonstrated in the germline of only a few invertebrate species such as Drosophila, Caenorhabditis elegans, and the planarian Dugesia japonica (Parisi and Lin 2000; Salvetti et al. 2005). Furthermore, PUF proteins in different organisms and sometimes even in different tissues exhibit different selectivity in binding to their target RNAs and in executing different regulatory impacts toward their target RNAs (Quenault et al. 2011). The versatility and specificity of PUF proteins underscore the importance of investigating the function and action mechanism of PUF proteins in mammalian systems. However, few such studies have been conducted. We focused especially on the mammalian nervous system because post-transcriptional regulation is known to play crucial roles in neurogenesis (Pilaz and Silver 2015), but this type of mechanism has not been well explored in general. Particularly relevant to our study is a recent report on a paradigmatic neurodegenerative proteinopathy termed spinocerebellar ataxia type 1, in which the expression of the mutant Ataxin 1 protein in neurons causes toxicity, leading to progressive deterioration of motor coordination (Gennarino et al. 2015). Gennarino et al. (2015) discovered that Pum 1 directly represses ATAXIN1 expression and thus plays an important role in motor function and in preventing neurodegeneration. These important discoveries also highlight the clear need to investigate Pum1 and Pum2 function in normal neurogenesis. Our analysis filled this void and demonstrated the important role of Pum 1 and Pum 2 in neurogenesis, especially in hippocampal development and function.

Because our conditional knockout mice depleted Pum1 and Pum 2 from the nervous system since the beginning of neurogenesis, the observed defects in the DG as the most obvious phenotype in the Ndcko mutant mice represent a major function of Pum 1 and Pum2 in hippocampal neurogenesis and perhaps the most important function of Pum1 and Pum 2 in the brain. Our study revealed a collective function of Pum1 and Pum2, advancing the knowledge of Pum2 function in the mouse nervous system (Siemen et al. 2011). Depleting Pum 1 and Pum 2 in the neural system causes drastic reduction of the DG, mostly due to reduced number, survival, and proliferation of NSCs in the DG. These stem cell defects were confirmed by the neurosphere assay. In addition, the mutant DG accumulates an excessive number of NPCs but contains fewer immature neurons. These observations reveal the key role of Pum1 and Pum 2 in promoting the establishment and self-renewing division of NSCs in the DG as well as the differentiation of their derivative neural progenitors into immature neurons. This biphasal function of Pum 1 and Pum 2 echoes their expression through the neural lineage. Furthermore, the important function of Pum1 and Pum 2 in hippocampal neurogenesis is expected to have a significant impact on learning and memory, since information storage relies on the generation and incorporation of newborn neurons in the hippocampus (Deng et al. 2010). Indeed, our behavioral tests of the Ndcko mice clearly demonstrated the important role of Pum 1 and Pum 2 for the survival of neurons (or NSPCs) and hippocampal neurogenesis, which in turn ensures normal learning and memory.
Pum1 and Pum2 regulate >2000 mRNAs, which may achieve their neural function

To fully understand how Pum proteins achieve their biological function, it is critical to find out how Puml and Pum2 regulate their target RNAs. A few conserved targets, including hunchback and cyclinB, have been discovered in the early studies of Pum and Nos (Wharton and Struhl 1991; Asaoka-Taguchi et al. 1999). However, the mRNA targets were not systematically identified until the advent of genomic approaches such as RIP-chip or deep sequencing (RIP-seq) and CLIP. RIP-chip has been applied to yeast PUFs (Gerber et al. 2004), mouse Pum1 in testes (Chen et al. 2012), and human Pum proteins in HeLa cells (Galgano et al. 2008) and revealed distinct populations of mRNAs enriched in diverse pathways. The development of the HITS-CLIP and iCLIP techniques allowed investigators to identify binding sites at singlenucleotide resolution. For example, photoactivatable ribonucleoside-enhanced CLIP (PAR-CLIP) of human Pum 2 using the 293 T cell line identified 3000 transcripts, more than any previous efforts (Hafner et al. 2010). Despite the large number of targets, all of these genomewide studies, including our work reported here, identified the same PUF-binding motif (UGUGHAUA), consistent with the conserved PRE.

Our triplicate iCLIP analysis identified 1874 targets for Pum 1 and 875 targets for Pum2. They form an overlapping set of 694 common targets, suggesting the overlapping of their functions and explaining their partial functional redundancy. The iCLIP technique also enabled us to reveal the strong binding preference toward the 3' UTR for both Pum1 and Pum2. Interestingly, besides binding to the mRNAs, we also discovered a number of binding sites in the noncoding RNA (ncRNA) regions for both Pum1 and Pum2, with such sites much more enriched for Pum2 than Pum1. These noncoding binding sites might be indicative of Pum1 and Pum2 binding to long ncRNAs (lncRNAs) that contain these sites. Indeed, recent work has discovered the interplay between Pum proteins and lncRNAs in maintaining genomic stability (Lee et al. 2016; Tichon et al. 2016). Hence, our findings provide evidence for potential interaction between Pum proteins and many other ncRNAs as a distinct role of Pum 1 and Pum2 in gene regulation during neurogenesis and beyond.

Our GO analysis of Pum1 and Pum2 target mRNAs revealed their enrichment in multiple pathways that are critical in neurogenesis. Top terms were "cell adhesion" and "cell migration," both vital for proper neuronal proliferation, differentiation, and maturation (Hayashi et al. 2015). Cell adhesion is key to maintaining stem cells in their niche, yet cell migration is a key aspect of neuronal migration and projection development. Thus, the enrichment of the Pum targets in these pathways is consistent with the deficiency of the mutant in NSC establishment and self-renewal as well as in neuronal differentiation. Other pathways-including small GTPase-mediated signaling transduction, the Wnt signaling pathway, and neurotransmitter regulation, all of which play important roles in regulating NSC proliferation, differentiation, and 
survival-thus can also nicely explain the functions of Pum proteins in stem cell maintenance at early stages. Finally, it is worth noting that Pum proteins target regulatory pathways such as chromatin modification, regulation of transcription, and translation, suggesting that Puml and Pum 2 might regulate these regulators.

PUF proteins regulate diverse targets; however, different PUF proteins also exert different modes of regulation toward their targets. For example, yeast PUF protein Puf5p induces deadenylation-mediated mRNA turnover and translational repression by direct recruitment of the Ccr4-Pop2p-Not deadenylase complex (Goldstrohm et al. 2006). In contrast, C. elegans PUF protein FBF adopts a deadenylation-independent way to repress translation in which the PUF-Ago-eEF1A complex attenuates translation elongation by inhibiting eEF1A GTPase activity (Friend et al. 2012). Both Drosophila Pum and Xenopus Pum function by competing with eIF4E for $5^{\prime}$ cap structure recognition (Cho et al. 2005; Cao et al. 2010). Our examination of Pum target mRNAs and proteins encoded by a limited number of the targets indicates that the main function of Pum1 and Pum2 might be in translational repression, with a secondary function in regulating the stability of a small subset of mRNAs. Further studies are required to systematically address this question.

\section{Pum1 and Pum2 interact with FMRP in regulating neurogenesis}

Although the regulation of Pum1 and Pum2 toward 2055 target mRNAs represents a seemingly insurmountable challenge to further mechanistic studies, our identification of FMRP as a novel protein partner of Puml and Pum2 will likely provide an effective entry point for future studies. FMRP binds to target mRNAs with its $\mathrm{KH}$ binding domains and represses the translation from the mRNAs by interfering with translational initiation, stalling ribosomal translocation, and/or mediating RNAi (Santoro et al. 2012). FMRP is an important post-transcriptional regulator in neurogenesis, including the DG (Guo et al. 2011). Pum1 and Pum2 not only appear to interact with FMRP in the same complex but also bind to each other's mRNAs.

In addition, our observation of the similar but nonidentical phenotypes of Pum1 and Pum2 single-knockout animals (data not shown) as well as the overlapping but not identical target pools for Pum1 and Pum2 identified by iCLIP, suggest that Pum1 and Pum2 play similar but different roles in regulating neurogenesis. A recent study from Wang et al. (2016) discovered a unique protein partner, dynein light chain (DLC-1), for C. elegans FBF-2 that promotes its localization and function in germline progenitor maintenance but not for its highly similar homolog, FBF-1. Hence, different PUF proteins may have different protein partners to perform different functions.

\section{Materials and methods}

Generation and maintenance of Pum1 and Pum2 knockout mice

P1KO mice were generated as described by Chen et al. (2012). $\mathrm{P} 2 \mathrm{KO}$ mice were generated in a similar way, starting with a condi- tional knockout strategy to avoid possible embryonic lethality. A region in the Pum2 allele that contains exon 3 was flanked by LoxP sites by targeting the wild-type Pum2 allele in mouse embryonic stem cells. Mice in the B6/129 background that carry this allele were generated by the University of Connecticut Gene Targeting and Transgenic Facility. Pum $2^{\text {flox/flox }}$ mice were mated with a VASA-cre line in which Cre expression is confined to the gonads (Gallardo et al. 2007). Pum2 testis conditional knockout males (Pum2 ${ }^{-\mid f l o x} ;$ VASA-cre/+) thus generated were crossed with wildtype females. In this mating, the Pum2-null allele was transmitted through the male germline, and thus the resulting offspring were globally Pum2 $2^{+/-}$. Self-cross of Pum2 ${ }^{+/-}$mice gave rise to P2KO $\left(\right.$ Pum $\left.^{-1-}\right)$ mice and also maintained this strain.

Pum $1^{+/ f l o x} ;$ Pum $2^{+/ f l o x}{ }_{;}$Nestin-Cre $e^{+}$breeders were generated by crossing Pum1 and Pum2 LoxP mice with the Nestin-cre line [B6. Cg- $\mathrm{Tg}(\mathrm{Nes}-\mathrm{cre}) 1 \mathrm{~K} \ln / \mathrm{J}$; stock no:003771] from the Jackson laboratory (Tronche et al. 1999). Pum1 ${ }^{+/ f l o x}{ }_{;}$Pum $^{+/ f l o x}{ }_{i}$ Nestin-Cre $^{+}$ mice were bred with Pum flox/flox $;$ Pum $2^{\text {flox/flox }}$;Nestin-Cre ${ }^{-}$ mice to generate Pum1 ${ }^{+/ f l o x}{ }_{i}$ Pum ${ }^{+/ f l o x}{ }_{i}$ Nestin-Cre ${ }^{+}(\mathrm{Ctrl})$ and Pum1 $1^{\text {flox } / \text { flox }} ;$ Pum2 $2^{\text {flox/flox }}$;Nestin-cre $/+($ Ndcko) mice. Also see the Results.

The Fmr1 knockout female breeder (B6.129P2-Fmr1tm1Cgr/J; stock no:003025) was purchased from the Jackson laboratory (Bakker et al. 1994). She was bred with a B6/129 wild-type male to generate $\mathrm{Fmrl}^{+/-}$heterozygous females and $\mathrm{Fmr1} 1^{-} / \mathrm{Y}$ homozygous males. The $\mathrm{Fmrl}^{+/-}$female was then bred with the $\mathrm{Fmr1}^{-} / \mathrm{Y}$ male to generate $\mathrm{Fmr}^{+/-}$heterozygous and $\mathrm{Fmr} \mathrm{1}^{-/-}$homozygous females as well as $\mathrm{Fmrl}^{+} / Y$ wild-type males in the same litter for comparison.

\section{Immunoblotting}

For protein lysate preparation, the whole-brain tissues were ground with disposable pestles in 4 vol of Western blot lysis buffer (0.5\% NP40, 0.5\% TritonX-100, 0.15\% SDS, 50 mM HEPES at $\mathrm{pH}$ 7.4, protease inhibitor [Roche, 1697498001]), briefly frozen at $-80^{\circ} \mathrm{C}$, and thawed at room temperature followed by sonication (Bioruptor, medium strength, 20 shots) for thorough lysis. The lysates were then centrifuged at maximum speed for $5 \mathrm{~min}$ at $4^{\circ} \mathrm{C}$ to remove the debris. Protein concentrations were measured using BCA assay with the Pierce BCA protein assay kit (Thermo Fisher Scientific, 23225). Before loading the gel, the samples were mixed with $6 \times$ SDS loading buffer $(300 \mathrm{mM}$ Tris- $\mathrm{HCl}$ at $\mathrm{pH} 6.8,12 \%$ SDS, 30\% glycerol, $600 \mathrm{mM} \beta$-mercaptomethanol, $0.04 \%$ bromophenol blue) and boiled for $5-10 \mathrm{~min}$ at $95^{\circ} \mathrm{C}$.

Protein samples were run on $4 \%-15 \%$ precast polyacrylamide gels (Bio-Rad, 456-1085) in 1× Tris-glycine SDS-PAGE running buffer. Next, the $0.45-\mu \mathrm{m}$ nitrocellulose membrane (Bio-Rad, 162-0115) was used for semidry transfer. The membrane was blocked in $5 \%$ milk for $1 \mathrm{~h}$ at room temperature followed by overnight incubation in primary antibody at $4^{\circ} \mathrm{C}$. Dilutions of primary antibodies are listed in Supplemental Table S5. After incubation with primary antibody, the membrane was washed three times with TBST for 10 min each and incubated with the corresponding secondary antibody conjugated with HRP for $2 \mathrm{~h}$ at room temperature. The membrane was again washed three times with TBST for $10 \mathrm{~min}$ each and incubated in SuperSignal West Pico chemiluminescent substrate (Thermo Fisher Scientific, 34080) for $5 \mathrm{~min}$. Finally, the membrane was exposed to films and developed in the darkroom.

Immunofluorescence microscopy and brain stereology

The whole brain was dissected out fresh, fixed in $4 \%$ paraformaldehyde (PFA) overnight at $4{ }^{\circ} \mathrm{C}$ with rotation, and either embedded in $4 \%$ agarose and floating-sectioned into $45-$ to $60-\mu \mathrm{m}$ 
sections or OCT-embedded (Scigen, 4583) and cryo-sectioned into $10-\mu \mathrm{m}$ sections. For animals $>7 \mathrm{~d}$ post-partum, perfusion with $4 \%$ PFA was performed before sacrifice and dissection. The perfusion and sacrifice procedure was approved by the Yale Animal Resources Center.

For immunofluorescence, the slides were rehydrated in PBS for $5 \mathrm{~min}$. For antibodies that require antigen retrieval, the slides were then steamed in $0.01 \mathrm{M}$ sodium citrate buffer $(\mathrm{pH}$ 6.0) for $20 \mathrm{~min}$ and naturally cooled. The slides were then permeabilized in $0.3 \%$ Triton in PBS at room temperature for $15 \mathrm{~min}$ and washed in PBST ( $0.1 \%$ Tween in PBS) before being blocked in $5 \%$ normal donkey/goat serum for $1 \mathrm{~h}$ at room temperature and incubated in primary antibody in a humid chamber overnight at $4^{\circ} \mathrm{C}$. Dilutions of primary antibodies are listed in Supplemental Table S5. Secondary antibody was incubated for $2 \mathrm{~h}$ at room temperature. DAPI was stained for $5 \mathrm{~min}$ at room temperature. After primary and secondary antibody incubation, the slides were washed three times with PBST for 10 min each. Finally, mounting medium was added to the sections, and the slides were sealed with cover glass. Stained slides were imaged with either a Zeiss confocal microscope (for Pum1 and Pum 2 expression) or a Zeiss fluorescence microscope (for phenotype).

Brain stereology was performed by adapting the method described in Lu et al. (2001) and Han et al. (2015). Serial sections were stained with DAPI and imaged under a microscope. The DG region had a high cellular density and thus could be reliably defined. The borders of the DG were traced manually. The areas of the DG on five or six serial sections (enough to include the entire DG from anterior to posterior) were summed up and multiplied by the section interval $(50 \mu \mathrm{m} \times 5,250 \mu \mathrm{m} \times 6$, or $300 \mu \mathrm{m} \times$ 6) to estimate the volumes.

\section{Neurosphere assay}

Primary culture of NSCs was performed by adapting the protocol described in Šestan et al. (1999). First, the DG was microdissected from control or Ndcko neonatal mouse brains, minced, and dissociated enzymatically with PPD (papain-protease-DNase) solution $10.01 \%$ papain [Worthington Biochemical Corporation, LS003124], 0.1\% neutral protease [Dispase II; Sigma-Aldrich, D4693], 0.01\% DNase I [Sigma-Aldrich, D5025] in Hank's buffered salt solution [HBSS]) for $45-60 \mathrm{~min}$ at $37^{\circ} \mathrm{C}$. Dissociated cells were pelleted and washed with PBS and then plated in neurosphere medium $(2 \% \mathrm{~B} 27,100 \mathrm{U} / \mathrm{mL}$ penicillin-streptomycin in DMEM/F12 supplemented with $20 \mathrm{ng} / \mathrm{mL}$ EGF and bFGF [all from Thermo Fisher Scientific]). Neurospheres were passaged about once a week (Ndcko neurospheres were passaged about every $10 \mathrm{~d}$, as they grew much slower) using Accutase (Millipore, SCR005) for digestion and maintained up to three passages. For staining, the neurospheres were cytospun onto the slides at 600 $\mathrm{rpm}$ for $5 \mathrm{~min}$ and fixed in $4 \%$ PFA for $0.5 \mathrm{~h}$ at room temperature.

NSC differentiation was done on chamber slides (BD Falcon, 354108) coated with poly-L-ornithine (Sigma, P3655) for $2 \mathrm{~h}$ at $37^{\circ} \mathrm{C}$ and then laminin (Thermo Fisher Scientific, 23017015) overnight at $37^{\circ} \mathrm{C}$. Differentiation medium $(2 \%$ B27, 2 mM L-glutamine, $1 \mathrm{mM}$ sodium pyruvate, $5 \%$ FBS [fetal bovine serum], 100 $\mathrm{U} / \mathrm{mL}$ penicillin-streptomycin in neurobasal medium [all from Thermo Fisher Scientific]) was used to replace the neurosphere medium $24 \mathrm{~h}$ after cells were plated and was changed every $2 \mathrm{~d}$ for a total of $10 \mathrm{~d}$. Finally, the slides were stained for neuronal and glial markers.

\section{TUNEL analysis}

TUNEL analysis was performed using the ApopTag fluorescein in situ apoptosis detection kit (Millipore, S7110) according to the manufacturer's manual. Briefly, slides were first rehydrated in PBS and then treated with $20 \mu \mathrm{g} / \mathrm{mL}$ Proteinase K for $15 \mathrm{~min}$ at room temperature. After washing twice using PBS, TdT enzyme in working buffer was applied to the slides and allowed to react for $1 \mathrm{~h}$ at $37^{\circ} \mathrm{C}$. The poly-T tails thus added were visualized by incubation with an anti-digoxigenin antibody conjugated to FITC. Stained slides were imaged on a Zeiss fluorescence microscope.

\section{Lashley III maze}

The Lashley III maze tests were performed following the protocol described in Bressler et al. (2010). The maze was borrowed from Dr. Gretchen Hermes and was constructed following the parameters described in the original protocol. Briefly, each day, the animals were moved to the behavioral testing room $0.5 \mathrm{~h}$ before the test for acclimation. Next, each mouse was placed in the start box and voluntarily explored the maze until it got to its corresponding pseudo-home cage. For each mouse, we recorded the time it spent in the maze, the number of errors it made, and the number of days it took to learn. Errors were defined as entries into a dead end zone or travelling back through an already travelled arm of the maze. A mouse was considered as having learned the maze when it reached the goal box with zero or one error on two consecutive trials. We performed one trial per animal per day on 15 consecutive days. Mice were tested in the same order on successive trials.

\section{iCLIP}

iCLIP was performed following the protocol described in Konig et al. (2011). For each condition (namely, WT_PliCLIP, P1KO_P1iCLIP, WT_P2iCLIP, and P2KO_P2iCLIP), five to 10 whole neonatal brains were pooled together to obtain $0.5 \mathrm{~g}$ of starting materials for one biological replicate. Tissues were collected in $500 \mu \mathrm{L}$ of PBS and gently dissociated using disposable pestles. Dissociated tissues were moved to a $10-\mathrm{cm}$ dish, and 8 $\mathrm{mL}$ of ice-cold PBS was added. The dish was placed on an icebox and, with the lid removed, irradiated twice for $400 \mathrm{~mJ} / \mathrm{cm}^{2}$ in a Stratagene Stratalinker 1800 at $254 \mathrm{~nm}$. Next, the sample was transferred into a $15-\mathrm{mL}$ Falcon tube and pelleted at $1000 \mathrm{~g}$ for 5-10 min at $+4^{\circ} \mathrm{C}$. Supernatant was removed, and the pellets were snap-frozen in liquid nitrogen and stored at $-80^{\circ} \mathrm{C}$ until use.

On the day of the experiment, tissues pellets were thawed on ice, resuspended in $1 \mathrm{~mL}$ of lysis buffer, and transferred to a 1.5$\mathrm{mL}$ Eppendorf tube. Sonication was done with the Bioruptor for six pulses of $10 \mathrm{sec}$ each at medium strength with 20 -sec pauses. Tissues were then spun at maximum speed for $10 \mathrm{~min}$ at $+4^{\circ} \mathrm{C}$ to remove the debris.

Partial RNA digestion was performed before immunoprecipitation with a $10^{-6}$ dilution of RNase1 (Ambion, AM2295) for Pum1 iCLIP and a $10^{-8}$ dilution for Pum2 iCLIP. The lysates were first precleaned with $10 \mu \mathrm{L}$ of Dynabeads Protein G and then incubated with $30 \mu \mathrm{L}$ of Pum1 antibody (Abcam, 92545) or $15 \mu \mathrm{L}$ of Pum2 antibody (Abcam, 92390) for $4 \mathrm{~h}$ followed by the addition of $30 \mu \mathrm{L}$ of beads for another $4 \mathrm{~h}$.

All of the other steps and reagents that were not mentioned here were performed/purchased exactly as described in the protocol of Konig et al. (2011).

The prepared libraries were sequenced following standard Illumina protocols for 50-nt single-end runs. The steps of data preprocessing were done with in-house scripts: (1) demultiplexing samples, (2) trimming of $3^{\prime}$ and $5^{\prime}$ adaptor sequences, (3) removal of PCR replicates using random barcodes, and (4) removal of reads mapped to repeat annotated regions (RepeatMasker track in University of California at Santa Cruz [UCSC] genome browser, version $\mathrm{mm} 10)$. 
We then mapped the reads to the Mus musculus genome (UCSC $\mathrm{mm} 10$ ) and transcriptome (RefSeq) via TopHat and prefiltered out reads with multiple genomic alignments (with parameters - $M$-g 1). TopHat aligned reads to exon-exon junction sites to recover potential binding sites around exon-exon junctions. The majority of reads mapped to genic regions (Supplemental Table S1).

Identification of the binding sites was done using CITS following steps $88-113$ described in Moore et al. (2014). Briefly, the script searched for significant peaks by considering one specific genic region as a unit for permutations to estimate an expected peak height. A peak was called for a height compared with the expected height (with a $P$-value of $<0.001$ threshold).

Moreover, we looked for reproducible binding sites across duplicates, as reproducible sites can provide evidence of potential Pum bindings to transcripts. Peaks occurring in at least two replicates within a condition were called reproducible sites.

Finally, 30 base pairs was added to both sides of the reproducible binding sites for MEME to perform a de novo motif discovery. We performed GO analysis by DAVID version 6.7 and used the default mouse gene list as the background set.

RIP

For each condition in each biological repeat, one neonatal whole brain was homogenized in MCB buffer (150 mM KAc, $1 \%$ Triton $\mathrm{X}-100,1 \% \mathrm{NP} 40,50 \mathrm{mM}$ HEPES at $\mathrm{pH} 7.4,2 \mathrm{mM} \mathrm{MgAc} 2,10 \%$ glycerol, EDTA-free protease inhibitor, RNase inhibitor [Thermo Fisher Scientific, 10777019]), spun at maximum speed for $10 \mathrm{~min}$ to remove the debris, and precleared with $10 \mu \mathrm{L}$ of empty Dynabeads Protein G for $0.5 \mathrm{~h}$. Antibody was incubated with the lysates for $1 \mathrm{~h}$, and then $20 \mu \mathrm{L}$ of beads was added. The incubation of beads/antibodies/lysates was done with rotation at $4{ }^{\circ} \mathrm{C}$ overnight for Pum $1 / 2$ and for $3 \mathrm{~h}$ for Fmrp. Next, the beads were washed three times with MCB buffer, and the RNA was eluted using $1 \mathrm{~mL}$ of TRIzol (Thermo Fisher Scientific, 15596026) following the manufacturer's manual.

\section{qRT-PCR and RNA-seq}

For wild type, $\mathrm{P} 1 \mathrm{KO}$, and $\mathrm{P} 2 \mathrm{KO}$, the starting materials were $10 \%$ of the materials saved from the iCLIP experiment. For Ndcko, the starting materials were one neonatal whole brain for each biological repeat. Total RNA was extracted using RNeasy Plus kit (Qiagen, 74134) following the manufacturer's manual. For qRT-PCR, the RNA was converted to cDNA using the High-Capacity cDNA reverse transcription kit (Applied Biosystems, 4368814). One microgram of RNA was used for every $20 \mu \mathrm{L}$ of reverse transcription reaction mix. The following program was used for qPCR: 3 min at $95^{\circ} \mathrm{C}\left(15 \mathrm{sec}\right.$ at $95^{\circ} \mathrm{C}, 0 \mathrm{sec}$ at $55^{\circ} \mathrm{C}$, and $30 \mathrm{sec}$ at $\left.72^{\circ} \mathrm{C}\right)$ for $39 \mathrm{cy}-$ cles followed by melting curve measurement. The qPCR primers are listed in Supplemental Table S6. In each pair of primers, either one primer spanned an exon-exon junction, or the pair covered a region that included a large intron to preclude amplification of residual genomic DNA.

For RNA-seq, the libraries were constructed using the TruSeq stranded mRNA sample preparation kit (Illumina, RS-122-2101) and sequenced on an Illumina HiSeq 2000 platform. We aligned RNA-seq reads to $M$. musculus UCSC mm10 references with TopHat and calculated the FPKM (fragments per kilobase per million mapped fragments) of each gene with Cufflinks. The expression level of each gene was calculated as its FPKM. Differentially expressed genes were assessed with the Cuffdiff package at a false discovery rate (FDR) of $<0.05$.

The RNA-seq data in this work were deposited in the NCBI Gene Expression Omnibus (GEO) under accession number GSE95197.

\section{Coimmunoprecipitation}

For each condition in each biological repeat, one neonatal brain was homogenized in coimmunoprecipitation buffer $150 \mathrm{mM}$ KAc, $0.06 \%$ Triton X-100, 0.06\% NP40, $50 \mathrm{mM}$ HEPES at $\mathrm{pH}$ 7.4, $2 \mathrm{mM} \mathrm{MgAc2}$, 10\% glycerol, $1 \mathrm{mMDTT}$, EDTA-free protease inhibitor), spun to remove the debris, and precleared with $10 \mu \mathrm{L}$ of empty beads for $0.5 \mathrm{~h}$. Antibody was incubated with the lysates for $1 \mathrm{~h}$, and then $20 \mu \mathrm{L}$ of beads was added overnight at $4^{\circ} \mathrm{C}$ with rotation. Beads were then washed three times with coimmunoprecipitation buffer and eluted with SDS-PAGE loading buffer.

\section{Cellular fraction}

The protocol was adapted and modified from Wuarin and Schibler (1994). One wild-type neonatal whole brain was homogenized in $200 \mu \mathrm{L}$ of ice-cold NP-40 lysis buffer $(10 \mathrm{mM}$ Tris- $\mathrm{HCl}$ at $\mathrm{pH} 7.5$, $0.05 \% \mathrm{NP} 40,150 \mathrm{mM} \mathrm{NaCl}$ ) by pipetting and incubated for $5 \mathrm{~min}$ on ice. Next, the lysate was gently moved onto a layer of $2.5 \mathrm{vol}$ of chilled sucrose cushion (24\% sucrose in NP-40 lysis buffer) and centrifuged at $13,000 \mathrm{~g}$ for $10 \mathrm{~min}$ at $4^{\circ} \mathrm{C}$. The supernatant was collected as the cytoplasmic fraction, $3 \%$ of which was used for Western blot.

The nucleus pellets were rinsed with $1 \times$ PBS/ $1 \mathrm{mM}$ EDTA and then resuspended in $100 \mu \mathrm{L}$ of prechilled glycerol buffer $(20 \mathrm{mM}$ Tris- $\mathrm{HCl}$ at $\mathrm{pH} 7.9,75 \mathrm{mM} \mathrm{NaCl}, 0.5 \mathrm{mM}$ EDTA, $0.85 \mathrm{mM} \mathrm{DTT}$, $0.125 \mathrm{mM}$ PMSF, $50 \%$ glycerol) by gentle flicking of the tube. Next, an equal volume of cold nucleus lysis buffer (10 mM HEPES at $\mathrm{pH} 7.6,1 \mathrm{mM}$ DTT, $7.5 \mathrm{mM} \mathrm{MgCl}_{2}, 0.2 \mathrm{mM}$ EDTA, $0.3 \mathrm{M}$ $\mathrm{NaCl}, 0.2 \mathrm{M}$ urea, $0.2 \% \mathrm{NP}-40$ ) was added and vortexed vigorously followed by incubation for $5 \mathrm{~min}$ on ice. Finally, the lysate was centrifuged at $15,000 \mathrm{~g}$ for $3 \mathrm{~min}$ at $4^{\circ} \mathrm{C}$, and the supernatant was collected as the nucleoplasm fraction, $3 \%$ of which was used for Western blot.

The remaining pellet was chromatin and was gently rinsed with cold $1 \times$ PBS/ $1 \mathrm{mM}$ EDTA and treated with $2 \mu \mathrm{L}$ of DNase in $1 \times$ PBS with shaking at $500 \mathrm{rpm}$ for $10 \mathrm{~min}$ at $37^{\circ} \mathrm{C}$. Again, $3 \%$ of the chromatin fraction was used for Western blot.

\section{Polysome fractionation}

The protocol was adapted and modified from Merrick and Hensold (2001). Five wild-type neonatal brains were pooled together and lysed in TMK-100 lysis buffer (10 mM Tris- $\mathrm{HCl}$ at $\mathrm{pH} 7.4,5$ $\mathrm{mM} \mathrm{MgCl} 2,100 \mathrm{mM} \mathrm{KCl}, 1 \%$ TritonX-100, $0.5 \%$ sodium deoxycholate in nuclease free water; EDTA-free protease inhibitor and RNase inhibitor were added fresh) by disposable pestles and spun down at maximum speed for $10 \mathrm{~min}$ at $4^{\circ} \mathrm{C}$ to remove the debris.

The sucrose gradient was prepared $2 \mathrm{~d}$ in advance using $10 \%$ and $60 \%$ sucrose solutions $(10 \%$ or $60 \%$ sucrose, $100 \mathrm{mM} \mathrm{KCl}$, $5 \mathrm{mM} \mathrm{MgCl}_{2}, 2 \mathrm{mM}$ DTT, $20 \mathrm{mM}$ HEPES-KOH at pH $7.4 \mathrm{in} \mathrm{nu-}$ clease free water) and kept at $4^{\circ} \mathrm{C}$.

Clear tissue lysate was loaded onto the gradient and ultracentrifuged at 35,000 rpm with an SW40Ti rotor for $3 \mathrm{~h}$ and then fractioned with fraction collector with continuous monitoring of absorbance at $254 \mathrm{~nm}$. Forty-five fractions were collected.

\section{Size exclusion chromatography analysis in brains (FPLC)}

Five wild-type neonatal brains were pooled together, homogenized in $5 \mathrm{~mL}$ of lysis buffer $(150 \mathrm{mM} \mathrm{KAc}, 0.06 \%$ Triton X$100,0.06 \%$ NP40, $50 \mathrm{mM}$ HEPES at pH 7.4, $2 \mathrm{mM} \mathrm{MgAc}_{2}, 10 \%$ glycerol, $1 \mathrm{mM}$ DTT, EDTA-free protease inhibitor [Roche, 11873580001], RNase inhibitor [Thermo Fisher Scientific, 10777019]), and then spun down at $15,000 \mathrm{rpm}$ for $30 \mathrm{~min}$ at $4{ }^{\circ} \mathrm{C}$ to remove nuclei and debris. The cleared lysate was injected 
into an HPLC machine and fractionated into 120 2-mL fractions through a HiPrep Sephacryl 16/70 S-400 HR column. The 25th73th fractions were then examined by immunoblot analysis with $16 \mu \mathrm{L}$ loaded onto the gel using antibodies of interest.

\section{Acknowledgments}

We thank Dr. Jinah Han and Dr. June Hee Park in Dr. Jean-Leon Thomas's laboratory and Dr. Valentina Botti from Dr. Karla Neugebauer's laboratory for their generous sharing of reagents, guidance, and discussions on neural and iCLIP techniques, respectively. We are grateful to Professor Jean-Leon Thomas, Professor Angelique Bordey, Professor Karla Neugebauer, and Professor Sandra Wolin for their valuable comments toward the project. This work was supported by the G. Harold and Leila Y. Mathers Award and National Institutes of Health R01GM121386 to H.L., and MH103339, MH106934, MH109904, and MH110926 to N.S. During this work, M.Z. received the K.S. and Feli Lo Graduate Fellowship for Excellence in Stem Cell Research.

\section{References}

Ahmed S, Gan HT, Lam CS, Poonepalli A, Ramasamy S, Tay Y, Tham M, Yu YH. 2009. Transcription factors and neural stem cell self-renewal, growth and differentiation. Cell Adh Migr 3: 412-424.

Änkö M-L, Neugebauer KM. 2012. RNA-protein interactions in vivo: global gets specific. Trends Biochem Sci 37: 255-262.

Asaoka-Taguchi M, Yamada M, Nakamura A, Hanyu K, Kobayashi S. 1999. Maternal Pumilio acts together with Nanos in germline development in Drosophila embryos. Nat Cell Biol 1: 431-437.

Baines RA. 2005. Neuronal homeostasis through translational control. Mol Neurobiol 32: 113-121.

Bakker CE, Verheij C, Willemsen R, van der Helm R, Oerlemans F, Vermey M, Bygrave A, Hoogeveen A, Oostra BA, Reyniers E, et al. 1994. Fmr1 knockout mice: a model to study fragile $\mathrm{X}$ mental retardation. Cell 78: 23-33.

Bhardwaj RD, Curtis MA, Spalding KL, Buchholz BA, Fink D, Björk-Eriksson T, Nordborg C, Gage FH, Druid H, Eriksson PS, et al. 2006. Neocortical neurogenesis in humans is restricted to development. Proc Natl Acad Sci 103: 12564 12568.

Bressler A, Blizard D, Andrews A. 2010. Low-stress route learning using the Lashley III maze in mice. J Vis Exp. doi: 10.3791/ 1786.

Brown V, Jin P, Ceman S, Darnell JC, O'Donnell WT, Tenenbaum SA, Jin X, Feng Y, Wilkinson KD, Keene JD, et al. 2001. Microarray identification of FMRP-associated brain mRNAs and altered mRNA translational profiles in fragile X syndrome. Cell 107: 477-487.

Cao Q, Padmanabhan K, Richter JD. 2010. Pumilio 2 controls translation by competing with eIF4E for 7-methyl guanosine cap recognition. RNA 16: 221-227.

Carreira-Rosario A, Bhargava V, Hillebrand J, Kollipara RK, Ramaswami M, Buszczak M. 2016. Repression of Pumilio protein expression by Rbfox 1 promotes germ cell differentiation. Dev Cell 36: 562-571.

Cembrowski MS, Wang L, Sugino K, Shields BC, Spruston N. 2016. Hipposeq: a comprehensive RNA-seq database of gene expression in hippocampal principal neurons. Elife 5: e14997.
Chen D, Zheng W, Lin A, Uyhazi K, Zhao H, Lin H. 2012. Pumilio 1 suppresses multiple activators of p53 to safeguard spermatogenesis. Curr Biol 22: 420-425.

Cho PF, Poulin F, Cho-Park YA, Cho-Park IB, Chicoine JD, Lasko P, Sonenberg N. 2005. A new paradigm for translational control: inhibition via 5-3' mRNA tethering by Bicoid and the eIF4E cognate 4EHP. Cell 121: 411-423.

Crittenden SL, Bernstein DS, Bachorik JL, Thompson BE, Gallegos M, Petcherski AG, Moulder G, Barstead R, Wickens M, Kimble J. 2002. A conserved RNA-binding protein controls germline stem cells in Caenorhabditis elegans. Nature 417: 660-663.

Darnell JC, Van Driesche SJ, Zhang C, Hung KYS, Mele A, Fraser CE, Stone EF, Chen C, Fak JJ, Chi SW, et al. 2011. FMRP stalls ribosomal translocation on mRNAs linked to synaptic function and autism. Cell 146: 247-261.

DeBoer EM, Kraushar ML, Hart RP, Rasin MR. 2013. Post-transcriptional regulatory elements and spatiotemporal specification of neocortical stem cells and projection neurons. Neuroscience 248: 499-528.

Deng W, Aimone JB, Gage FH. 2010. New neurons and new memories: how does adult hippocampal neurogenesis affect learning and memory? Nat Rev Neurosci 11: 339-350.

Driscoll HE, Muraro NI, He M, Baines RA. 2013. Pumilio-2 regulates translation of $\mathrm{Na}(\mathrm{v}) 1.6$ to mediate homeostasis of membrane excitability. J Neurosci 33: 9644-9654.

Dubois NC, Hofmann D, Kaloulis K, Bishop JM, Trumpp A. 2006. Nestin-Cre transgenic mouse line Nes-Cre1 mediates highly efficient Cre/loxP mediated recombination in the nervous system, kidney, and somite-derived tissues. Genesis 44: 355-360.

Friend K, Campbell ZT, Cooke A, Kroll-Conner P, Wickens MP, Kimble J. 2012. A conserved PUF-Ago-eEF1A complex attenuates translation elongation. Nat Struct Mol Biol 19: 176-183.

Gage FH. 2000. Mammalian neural stem cells. Science 287: 1433-1438.

Galgano A, Forrer M, Jaskiewicz L, Kanitz A, Zavolan M, Gerber AP. 2008. Comparative analysis of mRNA targets for human PUF-family proteins suggests extensive interaction with the miRNA regulatory system. PLoS One 3: e3164.

Gallardo T, Shirley L, John GB, Castrillon DH. 2007. Generation of a germ cell-specific mouse transgenic Cre line, Vasa-Cre. Genesis 45: 413-417.

Gennarino VA, Singh RK, White JJ, De Maio A, Han K, Kim J-Y, Jafar-Nejad P, di Ronza A, Kang H, Sayegh LS, et al. 2015. Pumiliol haploinsufficiency leads to SCA1-like neurodegeneration by increasing wild-type ataxin1 levels. Cell 160: 1087-1098.

Gerber AP, Herschlag D, Brown PO. 2004. Extensive association of functionally and cytotopically related mRNAs with Puf family RNA-binding proteins in yeast. PLOS Biol 2: E79.

Goldstrohm AC, Hook BA, Seay DJ, Wickens M. 2006. PUF proteins bind Pop2p to regulate messenger RNAs. Nat Struct Mol Biol 13: 533-539.

Guo W, Allan AM, Zong R, Zhang L, Johnson EB, Schaller EG, Murthy AC, Goggin SL, Eisch AJ, Oostra BA, et al. 2011. Ablation of Fmrp in adult neural stem cells disrupts hippocampus-dependent learning. Nat Med 17: 559-565.

Hafner M, Landthaler M, Burger L, Khorshid M, Hausser J, Berninger $\mathrm{P}$, Rothballer A, Ascano M Jr, Jungkamp AC, Munschauer M, et al. 2010. Transcriptome-wide identification of RNAbinding protein and microRNA target sites by PAR-CLIP. Cell 141: 129-141.

Han J, Calvo C-F, Kang TH, Baker KL, Park JH, Parras C, Levittas M, Birba U, Pibouin-Fragner L, Fragner K, et al. 2015. Vascular 
endothelial growth factor receptor 3 controls neural stem cell activation in mice and humans. Cell Rep 10: 1158-1172.

Han J, Kim HJ, Schafer ST, Paquola A, Clemenson GD, Toda T, Oh J, Pankonin AR, Lee BS, Johnston ST, et al. 2016. Functional implications of miR-19 in the migration of newborn neurons in the adult brain. Neuron 91: 79-89.

Hayashi K, Kubo K-i, Kitazawa A, Nakajima K. 2015. Cellular dynamics of neuronal migration in the hippocampus. Front Neurosci 9: 135.

Juliandi B, Abematsu M, Nakashima K. 2010. Epigenetic regulation in neural stem cell differentiation. Dev Growth Differ 52: 493-504.

Keene JD. 2007. RNA regulons: coordination of post-transcriptional events. Nat Rev Genet 8: 533-543.

Kempermann G, Song H, Gage FH. 2015. Neurogenesis in the adult hippocampus. Cold Spring Harb Perspect Biol 7: a018812.

Konig J, Zarnack K, Rot G, Curk T, Kayikci M, Zupan B, Turner DJ, Luscombe NM, Ule J. 2011. iCLIP-transcriptome-wide mapping of protein-RNA interactions with individual nucleotide resolution. J Vis Exp doi: 10.3791/2638.

Lee S, Kopp F, Chang T-C, Sataluri A, Chen B, Sivakumar S, Yu H, Xie Y, Mendell JT. 2016. Noncoding RNA NORAD regulates genomic stability by sequestering PUMILIO proteins. Cell 164: 69-80.

Lehmann R, Nusslein-Volhard C. 1987. Involvement of the pumilio gene in the transport of an abdominal signal in the Drosophila embryo. Nature 329: 167-170.

Lehtinen MK, Walsh CA. 2011. Neurogenesis at the brain-cerebrospinal fluid interface. Annu Rev Cell Dev Biol 27: 653-679.

Lim DA, Alvarez-Buylla A. 2016. The adult ventricular-subventricular zone (V-SVZ) and olfactory bulb (OB) neurogenesis. Cold Spring Harb Perspect Biol 8: a018820.

Lin H, Spradling AC. 1997. A novel group of pumilio mutations affects the asymmetric division of germline stem cells in the Drosophila ovary. Development 124: 2463-2476.

Lu L, Airey DC, Williams RW. 2001. Complex trait analysis of the hippocampus: mapping and biometric analysis of two novel gene loci with specific effects on hippocampal structure in mice. J Neurosci 21: 3503-3514.

Lui JH, Hansen DV, Kriegstein AR. 2011. Development and evolution of the human neocortex. Cell 146: 18-36.

Luo Y, Shan G, Guo W, Smrt RD, Johnson EB, Li X, Pfeiffer RL, Szulwach KE, Duan R, Barkho BZ, et al. 2010. Fragile X mental retardation protein regulates proliferation and differentiation of adult neural stem/progenitor cells. PLoS Genet 6: e1000898.

Mak W, Fang C, Holden T, Dratver MB, Lin H. 2016. An important role of Pumilio 1 in regulating the development of the mammalian female germline. Biol Reprod 94: 134.

Merrick WC, Hensold JO. 2001. Analysis of eukaryotic translation in purified and semipurified systems. Curr Protoc Cell Biol 8: 11.9.1-11.9.26.

Ming GL, Song H. 2011. Adult neurogenesis in the mammalian brain: significant answers and significant questions. Neuron 70: 687-702.

Moore MJ, Zhang C, Gantman EC, Mele A, Darnell JC, Darnell RB. 2014. Mapping Argonaute and conventional RNA-binding protein interactions with RNA at single-nucleotide resolution using HITS-CLIP and CIMS analysis. Nat Protoc 9: 263-293.

Nord AS, Pattabiraman K, Visel A, Rubenstein JLR. 2015. Genomic perspectives of transcriptional regulation in forebrain development. Neuron 85: 27-47.

Parisi M, Lin H. 1999. The Drosophila pumilio gene encodes two functional protein isoforms that play multiple roles in germ- line development, gonadogenesis, oogenesis and embryogenesis. Genetics 153: 235-250.

Parisi M, Lin H. 2000. Translational repression: a duet of Nanos and Pumilio. Current Biology 10: R81-R83.

Pilaz L-J, Silver DL. 2015. Post-transcriptional regulation in corticogenesis: how RNA-binding proteins help build the brain. Wiley Interdiscipl Rev RNA 6: 501-515.

Quenault T, Lithgow T, Traven A. 2011. PUF proteins: repression, activation and mRNA localization. Trends Cell Biol 21: 104-112.

Rakic P. 1985. Limits of neurogenesis in primates. Science 227: 1054-1056.

Ramasamy S, Narayanan G, Sankaran S, Yu YH, Ahmed S. 2013. Neural stem cell survival factors. Arch Biochem Biophys 534: $71-87$.

Saffary R, Xie Z. 2011. FMRP regulates the transition from radial glial cells to intermediate progenitor cells during neocortical development. J Neurosci 31: 1427-1439.

Salvetti A, Rossi L, Lena A, Batistoni R, Deri P, Rainaldi G, Locci MT, Evangelista M, Gremigni V. 2005. DjPum, a homologue of Drosophila Pumilio, is essential to planarian stem cell maintenance. Development 132: 1863-1874.

Santoro MR, Bray SM, Warren ST. 2012. Molecular mechanisms of fragile X syndrome: a twenty-year perspective. Annu Rev Pathol 7: 219-245.

Šestan N, Artavanis-Tsakonas S, Rakic P. 1999. Contact-dependent inhibition of cortical neurite growth mediated by notch signaling. Science 286: 741-746.

Shibata M, Gulden FO, Sestan N. 2015. From trans to cis: transcriptional regulatory networks in neocortical development. Trends Genet 31: 77-87.

Siemen H, Colas D, Heller HC, Brustle O, Pera RA. 2011. Pumilio-2 function in the mouse nervous system. PLoS One 6: e25932.

Silbereis JC, Pochareddy S, Zhu Y, Li M, Sestan N. 2016. The cellular and molecular landscapes of the developing human central nervous system. Neuron 89: 248-268.

Spassov DS, Jurecic R. 2003a. Mouse Pum1 and Pum2 genes, members of the Pumilio family of RNA-binding proteins, show differential expression in fetal and adult hematopoietic stem cells and progenitors. Blood Cells Mol Dis 30: $55-69$.

Spassov DS, Jurecic R. 2003b. The PUF family of RNA-binding proteins: does evolutionarily conserved structure equal conserved function? IUBMB Life 55: 359-366.

Tichon A, Gil N, Lubelsky Y, Havkin ST, Lemze D, Itzkovitz S, Stern-Ginossar N, Ulitsky I. 2016. A conserved abundant cytoplasmic long noncoding RNA modulates repression by Pumilio proteins in human cells. Nat Commun 7: 12209.

Tronche F, Kellendonk C, Kretz O, Gass P, Anlag K, Orban PC, Bock R, Klein R, Schutz G. 1999. Disruption of the glucocorticoid receptor gene in the nervous system results in reduced anxiety. Nat Genet 23: 99-103.

Uyhazi KE. 2012. "Pumilio proteins regulate translation in embryonic stem cells and are essential for early embryonic development." Ph.D. thesis. Yale University, New Haven.

Vessey JP, Vaccani A, Xie Y, Dahm R, Karra D, Kiebler MA, Macchi P. 2006. Dendritic localization of the translational repressor Pumilio 2 and its contribution to dendritic stress granules. J Neurosci 26: 6496-6508.

Vessey JP, Schoderboeck L, Gingl E, Luzi E, Riefler J, Di Leva F, Karra D, Thomas S, Kiebler MA, Macchi P. 2010. Mammalian Pumilio 2 regulates dendrite morphogenesis and synaptic function. Proc Natl Acad Sci 107: 3222-3227. 
Wang X, Olson JR, Rasoloson D, Ellenbecker M, Bailey J, Voronina E. 2016. Dynein light chain DLC-1 promotes localization and function of the PUF protein FBF-2 in germline progenitor cells. Development 143: 4643-4653.

Wharton RP, Struhl G. 1991. RNA regulatory elements mediate control of Drosophila body pattern by the posterior morphogen nanos. Cell 67: 955-967.

Wickens M, Bernstein DS, Kimble J, Parker R. 2002. A PUF family portrait: $3^{\prime} \mathrm{UTR}$ regulation as a way of life. Trends Genet 18: $150-157$.

Wuarin J, Schibler U. 1994. Physical isolation of nascent RNA chains transcribed by RNA polymerase II: evidence for cotranscriptional splicing. Mol Cell Biol 14: 7219-7225.

Zamore PD, Williamson JR, Lehmann R. 1997. The Pumilio protein binds RNA through a conserved domain that defines a new class of RNA-binding proteins. RNA (New York, NY) 3: 1421-1433.

Zhang B, Gallegos M, Puoti A, Durkin E, Fields S, Kimble J, Wickens MP. 1997. A conserved RNA-binding protein that regulates sexual fates in the C. elegans hermaphrodite germ line. Nature 390: 477-484.

Zhang Y, Chen K, Sloan SA, Bennett ML, Scholze AR, O'Keeffe S, Phatnani HP, Guarnieri P, Caneda C, Ruderisch N, et al. 2014. An RNA-sequencing transcriptome and splicing database of glia, neurons, and vascular cells of the cerebral cortex. I Neurosci 34: 11929-11947.

Zheng X, Boyer L, Jin M, Mertens J, Kim Y, Ma L, Ma L, Hamm M, Gage FH, Hunter T. 2016. Metabolic reprogramming during neuronal differentiation from aerobic glycolysis to neuronal oxidative phosphorylation. Elife 5: e13374. 


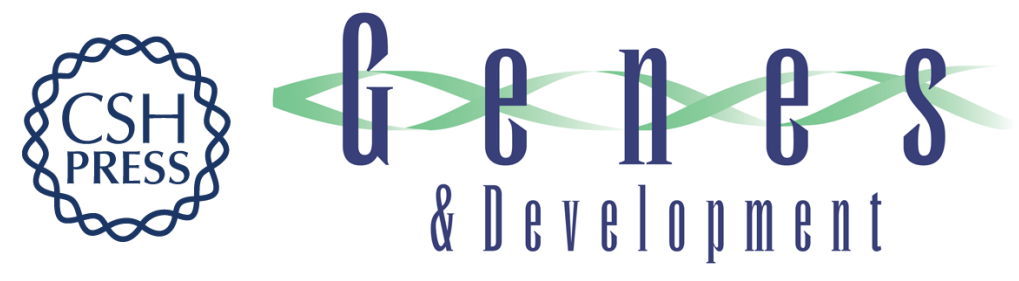

\title{
Post-transcriptional regulation of mouse neurogenesis by Pumilio proteins
}

\author{
Meng Zhang, Dong Chen, Jing Xia, et al.
}

Genes Dev. 2017, 31: originally published online August 9, 2017

Access the most recent version at doi:10.1101/gad.298752.117

\section{Supplemental http://genesdev.cshlp.org/content/suppl/2017/08/09/gad.298752.117.DC1 Material}

References This article cites 75 articles, 19 of which can be accessed free at: http://genesdev.cshlp.org/content/31/13/1354.full.html\#ref-list-1

Creative This article is distributed exclusively by Cold Spring Harbor Laboratory Press for the first Commons six months after the full-issue publication date (see

License http://genesdev.cshlp.org/site/misc/terms.xhtml). After six months, it is available under a Creative Commons License (Attribution-NonCommercial 4.0 International), as described at http://creativecommons.org/licenses/by-nc/4.0/.

Email Alerting Receive free email alerts when new articles cite this article - sign up in the box at the top Service right corner of the article or click here.

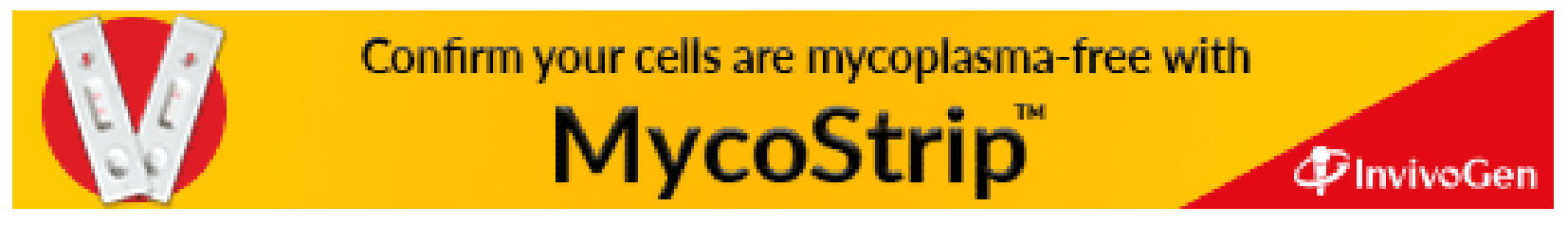

